\title{
El Brasil en la Barcelona de postguerra
}

\author{
JoRdi CERdÀ SUBIRACHS \\ Universitat Autònoma de Barcelona (Espanya) \\ orcid.org/0000-0002-0451-0193 \\ Presentació: 15 jul. 2018 | Acceptació: 5 oct. 2018 | Publicació: 15 des. 2018
}

Citació recomanada: Cerdà Subirachs, Jordi. 2018. «El Brasil en la Barcelona de postguerra». Dictatorships \& Democracies. Journal of History and Culture 6: 9-50. doi: https://dx.doi.org/10.7238/ dd.voi6.3149.

Resum: L’article pretén presentar la recepció de la poesia brasilera en el context català de la primera postguerra. Les autoritats franquistes van propiciar un nou marc de relacions culturals amb el continent americà i, concretament, amb el Brasil. L'emergència política i econòmica d'aquest país durant aquest període el va convertir també en un pol atractiu per a molts catalans. Si bé ha estat prou reconeguda la figura de João Cabral de Melo com a mitjancer cultural, cal situar-lo en un context molt més dinàmic i participat per altres agents com Raul Bopp, Alfonso Pintó o Rafael Santos Torroella. El combat polític i estètic del poeta brasiler per assolir un espai propi, singularitzat respecte a la seva pròpia tradició, convertirà Barcelona i la cultura catalana en un dels seus principals camps de maniobra. En aquest treball s'editen dues cartes de Cabral de Melo a Joan Brossa, en què es fa explícita la voluntat interventora del poeta brasiler en la cultura catalana del moment.

Paraules clau: recepció, poesia brasilera, surrealisme, postguerra, Dau al Set, João Cabral de Melo Neto, Raul Bopp, Murilo Mendes, Alfonso Pintó, Rafael Santos Torroella, Joan Brossa

\section{Brazil in Post-war Barcelona}

Abstract: This paper aims to present the reception of Brazilian poetry in the Catalan context of the first post-war period. The Francoist authorities fostered a new framework for cultural relations with the American continent, especially with Brazil. The political and economic emergence of this country during this period also made it an attractive spot for many Catalans. Although the figure of João Cabral de Melo as a cultural mediator is undeniably recognized, it must be placed in a context which is much more dynamic and in which other agents such as Raul Bopp, Alfonso Pintó or Rafael Santos Torroella played an important role too. The political and aesthetic struggle of the Brazilian poet to find a singular space within his own tradition turned Barcelona and the Catalan culture into one of his main training grounds. This paper edits two letters from Cabral de Melo to Joan Brossa, in which the will of the Brazilian poet to get involved in the Catalan culture of the moment is made explicit. 
Keywords: reception, Brazilian poetry, Surrealism, post-war period, Dau al Set, João Cabral de Melo Neto, Raul Bopp, Murilo Mendes, Alfonso Pintó, Rafael Santos Torroella, Joan Brossa

\author{
Como todo o real \\ é espesso \\ João Cabral de Melo, \\ O cão sem plumas (Barcelona, 1950)
}

Les relacions entre la cultura brasilera i la catalana disposen d'un lloc comú reiterat i explorat: la presència de João Cabral de Melo Neto en la Barcelona de la immediata postguerra. Al voltant de la seva activitat durant aquest curt però intens període s'han escrit un seguit d'articles i monografies tant des de la perspectiva brasilera com des de la catalana i espanyola. Tot i reconèixer-ne el paper central en la mediació d'ambdues cultures, caldria admetre que no hi té un paper exclusiu. Altres noms, altres recorreguts s'hi han d'afegir per poder calibrar la importància de la cultura brasilera a Catalunya i també, és clar, la presència de la cultura catalana al Brasil. De fet, el recorregut de Cabral de Melo pateix un desequilibri evident: disposem d'una informació i una crítica importants al voltant del primer període quan és enviat en missió consolar a Barcelona (1947-1950), però, per contra, poca cosa sabem de la seva activitat cultural a la nostra ciutat a final de la dècada dels seixanta, quan va ocupar el càrrec de cònsol general del Brasil (1967-1969). Sembla com si el seu paper de mitjancer cultural es desplacés a d'altres indrets de la Península, concretament a Sevilla i Madrid, i Barcelona quedés relegada a l'etapa preliminar del seu periple espanyol, que s'exhauriria en la segona etapa.

Una exposició més policèntrica de la relació Brasil-Catalunya podria esmenar cert reduccionisme a què s'ha arribat. El descobriment de la cultura brasilera va ser més participat entre els diversos agents de la Barcelona de la segona meitat del segle xx. El relat d'aquells anys tendeix, com és natural, a fer sobresortir les figures o esdeveniments que gaudeixen d'un ampli i consensuat reconeixement actual. És així, doncs, que la relació de Cabral de Melo amb els membres del Dau al Set, Joan Miró, Carles Riba o Cobalto, per exemple, té un efecte revaloritzador en ambdues parts. L'ombra, però, cau damunt de personatges o iniciatives que a pesar de la 
tenacitat i la perseverança dipositades en el seu moment, no disposen de gaire o de cap (re)coneixement.

L'anàlisi de la cultura barcelonina als anys de la immediata postguerra exigeix una constant revisió. L'actualitat d'unes dècades marcades encara per una repressió ferotge ha fet que la història cultural no s'hagi pogut estalviar els esculls que va imposar el règim franquista i les problemàtiques que se'n deriven. Represa, clandestinitat o censura són constants en els relats de les històries culturals i se solapen a atansaments d'índole més nítidament estètica. En efecte, la urgència dels temps encara va fer més evident la indissoluble unitat entre la literatura i la història. Però això no ens pot dispensar d'una aproximació més directa a la creació artística d'aquells anys no tan canalitzada pels recorreguts ideològics o nacionals, per les estratègies grupals que ulteriorment van assolir el reconeixement crític 0 pel seguiment de les grans figures que, ab ovo, en la fase de creació del seu

«geni», han absorbit l'atenció d'aquest període. Com va assenyalar Adorno, les obres d'art són la historiografia, inconscient d'ella mateixa, de la seva època. S'ha de mostrar la vitalitat d'un moment, sense desdenyar-ne la confusió; mostrar les múltiples vies d'accés a un ventall de dinàmiques culturals, sense menystenir-ne les limitacions.

\section{El marc de relacions}

Són pocs els referents que testimonien el coneixement de la literatura brasilera a Catalunya durant les primeres dècades del segle xx. Tanmateix, és a Barcelona - i concretament a l'editorial Maucci a l'entorn del 1917- on es publica el Parnaso Brasileiro d'Afonso Costa, una antologia poètica en llengua portuguesa, raó per la qual devem suposar l'escassíssima recepció que va tenir al nostre país. Aquest volum s'integrava en una collecció de recopilatoris de poesia de diversos indrets llatinoamericans —Argentina, Cuba, Xile o Veneçuela — que palesen la voluntat de l'editorial barcelonina d'obrir-se a mercats de l'altra banda de l'Atlàntic. Al Parnaso Brasileiro encara domina un indigenisme romàntic i excelleix Olavo Bilac, o príncipe dos poetas brasileiros, que entonava l'«Última flor do Lácio». És difícil assegurar que el Brasil disposés d'una imatge de modernitat prou definida a Catalunya i a Espanya abans de la Guerra Civil. Deu ser DICTATORSHIPS \& DEMOCRACIES 6 (2018) · E-ISSN: $2564-8829$ · PUNCTUM, UNIVERSITAT OBERTA DE CATALUNYA \& FUNDACIÓ CARLES PII SUNYER 
la revista Helix (1929-1930) de Vilafranca del Penedès, dirigida per Juan Ramón Masoliver, la primera que va dedicar l'any 1929 un interessant article a Heitor Villa-Lobos i en va reproduir la partitura de Chôros número 11. Aquell mateix any, el compositor brasiler va publicar a Helix l'article «O meu maior desejo é ver a música hespanhola livre de influências» en l'original portuguès i amb la seva traducció catalana. ${ }^{1}$ La revista vilafranquina, seguint la consigna de bona part de les publicacions d'avançada, mostrava així una inequívoca voluntat d'internacionalització. Una estratègia compartida per la revista madrilenya Gaceta Literaria, que va participar activament en la modernització cultural peninsular fent valer una vocació iberista i atlantista. I és en aquesta direcció que publica, l'any 1930 per exemple, una «Estructura de la actual poesía brasileña», signada per l'escriptor xilè Gerardo Seguel, que s'acompanya de les traduccions de quinze poetes brasilers. ${ }^{2}$

La irrupció de la nova poesia brasilera en el marc cultural barceloní i hispànic del primer franquisme és molt matinera. La revista dirigida també per Juan Ramón Masoliver i Fernando Gutiérrez, Entregas de Poesía $(\mathrm{V}, 1944)$, va publicar una antologia, només en llengua portuguesa, de «Cinco poetas brasileños de hoy». ${ }^{3}$ Com el mateix Masoliver va recordar

1 Ramon Borràs Prim assegurava que «En Mompou autor d'Altitud és devot de Villa-Lobos» (Borràs 1929, 2). Després, el mateix Villa-Lobos, de visita a la capital catalana en ocasió de l'Exposició Universal, va publicar per a Helix «O meu maior desejo...» amb la següent nota editorial de la revista, que revela l'autor de la traducció catalana: «La nostra revista, que presentà, per primera vegada a Espanya, Villa-Lobos - mercès als coneixements del viollinista Ramon Borràs Prim-demanà al compositor brasiler aprofitant la seva estada a Barcelona, un article. En colaborar-hi manifestà gran interès en que es publiqués en català: J[uan]. R[amón]. M[asoliver]. encarregat d’aquesta tasca en surt responsable.» (Villa-Lobos 1929, 3).

2 Els poetes antologats són: Oswald de Andrade, Mário de Andrade, Ronald de Carvalho, Guilherme de Almeida, Álvaro Moreyra, Menotti del Picchia, Francisco Karam, Cecília Meirelles, Gilka Machado, Murillo Araujo, Augusto Meyer, Jorge de Lima, Felipe de Oliveira, Barreto Filho i Tasso da Silveira. En aquesta panoràmica hi ha un esment obligat al moviment antropofàgic brasiler, si bé des d'un cert distanciament crític: «nació la tendencia elaborada en torno a la revista de Antropofagia, de São Paulo; ahí Oswald y Mário de Andrade dan sus mejores obras, constituyendo su credo doctrinario primitivista, sin que por ello pueda descuidarse al observador el escepticismo que en el fondo de su propia obra se vuelve contra su propia doctrina» (Seguel 1930, 5).

3 Els poetes i els poemes seleccionats són Jorge de Lima — «Adeus, poesia», «O Nome da Musa», «Lámpada Marina»—, Tasso da Silveira — «Piedade», «Humildade», «Gênese», «As Multitudões», «Crepúsculo»-, Adalgisa Nery — «u em Ti», «Fragmento»—, Alphonsus de Guimaraens Filho — «Ventos da tarde», «Junto ao corpo morto do Senhor»—i Vinícius de Moraes — «A Vida Vivida». Un dels trets 
el 1987, Alberto de Serpa, poeta portuguès del grup de la revista Presença i mitjancer destacat entre els diversos sistemes culturals ibèrics, el va posar en contacte amb el poeta e diplomata Vinícius de Moraes. Serpa havia acabat de publicar a Portugal una antologia de poesia brasilera que podia haver motivat l'interès de Masoliver i alhora oferir-li els contactes de primera mà dels poetes americans més destacats del moment. ${ }^{4}$ Malgrat que a l'extensa antologia de Serpa hi figuraven les veus més representatives de l'avantguarda brasilera, la tria d'Entregas de Poesía se centrava exclusivament en una estètica postsimbolista i marcadament catòlica.

Sigui com sigui, Masoliver va mantenir un interès continuat per la cultura d'aquest país sud-americà i puntualment tindrà un paper clau en la seva difusió a Espanya. Per bé que Entregas de Poesía era «la revista para pocos», Martí de Riquer dixit, la collecció «Poesía en la Mano», també dirigida per Masoliver, era l'empresa divulgadora d'una diversitat d'estils, èpoques i procedències líriques. Un dels dos volums de la sèrie «Poetas portugueses» (no cap a poetes brasilers) és el d'António Ferreira a cura de Manuel Segalà. Segalà és un nom vinculat al grup de poetes catalans en castellà que es van donar a conèixer durant la dècada dels quaranta. Associat sovint a Juan Eduardo Cirlot i comptat entre la nòmina surrealista, va acabar els seus dies al Brasil, on va desenvolupar una breu però destacada carrera com a impressor i gravador (Miranda s/d). En la introducció al volum dedicat a Ferreira, Segalà hi dibuixa un perfil en el més estricte

més destacats d'aquesta selecció és el catolicisme militant d'alguns d'aquests poetes. Jorge de Lima havia estat traduït al castellà el 1939 amb una presentació de Georges Bernados. Els tres poemes escollits de Lima són extrets del llibre A Túnica inconsútil (1938); certament, l'adjectiu "inconsútil", rar i gairebé sempre aplicat a la túnica sagrada, tindrà aviat, justament a Barcelona i de la mà de Cabral de Melo, una referència ben distinta. Per bé que no se'ns indica la procedència de tots els poemes, sí que es fa explícit que un poema de Tasso da Silveira és inèdit.

4 Alberto de Serpa havia publicat As melhores poesias brasileiras; la selecció, el prefaci i les notes eren a càrrec d’A. de Serpa (Lisboa: Portugália, 1943). «Fue una explosión cuando de esta parte del mar, metidos ya en la Guerra Mundial, se comprobó que la mejor poesía en lengua portuguesa la estaban escribiendo en el Brasil. A través del poeta portugués Alberto de Serpa conecté con el poeta y diplomático Vinícius de Moraes, quien compiló, para nuestras Entregas de Poesía (1944), una breve muestra, en portugués y con algún inédito, de su poesía y la de otros cuatro compatriotas: Jorge de Lima, Tasso da Silveira, Adalgisa Neri y Alphonsus de Guimaraens Filho» (Masoliver 1987, 22). Alberto de Serpa té una activitat destacada com a mitjancer entre Portugal i Espanya, sobretot arran de la seva participació al Congreso de Poesía de Segòvia, com més endavant veurem. A Entregas de poesía li van publicar uns poemes inèdits només en portuguès amb el títol de Nocturnos. 
i oficial classicisme. Les dèries imperialistes del moment, el garcilasismo omniscient, busquen la complicitat del Portugal salazarista i agermanen tots dos projectes totalitaris en un sol «destino en lo universal». Dit d'altra manera, l'aproximació entre els dos estats i les dues llengües no era innocent, sinó que formava part de l'estratègia política i cultural feixista. ${ }^{5}$

En el context de la Segona Guerra Mundial, l'acció diplomàtica franquista va promoure una idea d'hispanisme, substitutòria d'un suspecte panhispanismo, que ben aviat es va incorporar al discurs historiogràfic. ${ }^{6}$ La inauguració del nucli barceloní de l'Instituto de Estudios Hispánicos el 15 de maig de 1948, que va comptar amb la presència i amb el discurs del ministre d'Afers Estrangers, Alberto Martín Artajo, en corrobora la importància estratègica.7 L'ascendència que es volia atorgar al component

5 Segalà va escriure: «Estableciendo así la base de la futura poesía portuguesa, en movimiento parejo y contemporáneo del de Garcilaso y Boscán en la España del César» (Segalà 1940, 14). És prou evident la reivindicació que la revista Entregas de Poesía va fer d'autors portuguesos (i algun de català) d'expressió literària castellana. Així, el primer autor editat de la revista (gener de 1944) és el poeta barroc portuguès Paulo Gonçalvez de Andrada, no gaire difós i testimoni de la indefugible empremta gongorina. A Entregas de Poesía també es va publicar una mostra de lírica castellana d'un altre poeta portuguès del període filipí, Francisco de Portugal (1584-1632). Sembla, doncs, remarcable que la revista recuperés poetes portuguesos en castellà (també de catalans en castellà, com és el cas de Joan Boscà), a la qual, de fet, s'hi hauria d'incorporar un altre nom: Gregorio Silvestre. Aquest poeta portuguès de naixement i castellà d'expressió va merèixer un volum de «Poesía en la Mano» dins la sèrie «Poetas españoles», núm. 8 (1940).

6 Jaume Vicens Vives afirmava en un manual de geopolítica —en plena Segona Guerra Mundial— que l'ascendència natural d'Espanya al món passava per la seva projecció a l'Amèrica del Sud: «África será quizás el continente del futuro. Pero América del Sur es el continente del presente immediato, donde se concentran los intereses de Europa, Asia y América del Norte [...] En este aspecto, España no pude limitarse a ser la cabeza de puente de América en Europa. Ha de recabar para si sola, exclusivamente, el honor y la gloria de estructurar la Hispanidad en el Universo» (Vicens 1940, 211). Per a una visió de conjunt de l'acció diplomàtica i cultural de l'estat franquista a hispanoamèrica, vegeu Delgado (1992). És especialment aclaridor, pel que fa als orígens d'aquesta política hispanista a les primeres dècades del segle xx, el capítol «Imperialismo esencialmente pacífico e intelectual» (Delgado 1992, 47-70), i pel que fa al nou concepte d'hispanitat, «España, "avanzada de Europa en América”: Hispanidad versus Panamericanismo» (Delgado 1992, 285-303).

7 En aquest sentit, vegeu el fullet Instituto de Estudios Hispánicos de Barcelona (1948), que exposa el programa i els fonaments d'aquesta institució clau en la política econòmica i també cultural espanyola d'aquell període. S'hi pondera la tasca d'una altra institució barcelonina, la Casa Amèrica, que, «presidida por el egregio patricio, Federico Rahola», ja va marcar uns objectius dels quals se sentia hereva. Se'n destaca, per exemple, la superació d'una «vacua retórica del latinoamericanismo de antaño» per un desacomplexat hispanisme que, en paraules del ministre Martín Artajo, assoleixi «hacer de la Hispanidad "una unidad de destino de la gran familia de los pueblos hispanos al servicio de la Cristiandad". Unidad de destino que lleva implícita la unidad de religión, de lengua, de espíritu, de 
hispànic projectat a Amèrica passava també pel reconeixement del Brasil i l'amistat amb el règim feixista portuguès en facilitava l'accés. Abans de les Biennals Hispanoamericanes, per exemple, el pintor Ramon Rogent havia fet estades a Portugal i hi havia exposat, convidat pel Secretariat de Propaganda Nacional del règim salazarista. Colleccionistes brasilers havien comprat obra seva i semblava tot disposat per fer un més que probable salt al Brasil, si no fos perquè la mort del pintor en accident automobilístic desbarataria aquests plans. ${ }^{8}$ Rogent va ser mestre de pintors. Entre els seus deixebles va destacar Joan Ponç, el qual precisament tindrà una etapa brasilera crucial en la seva personalitat artística (Cerdà 2013).

L'acostament entre el Brasil i Espanya durant aquest període té principalment una finalitat econòmica, però no desatén aspectes culturals. Una aproximació interessada si tenim en compte el bloqueig internacional a què es va sotmetre el règim franquista (Delgado 1988 i 1992). Al final de la dècada dels quaranta, des de l'ambaixada del Brasil a Madrid es pretenia la creació d'un institut de cultura brasilera i un programa de publicacions amb el propòsit de donar a conèixer la cultura del país americà a Espanya. Es van signar acords bilaterals que incloïen destacades accions d'intercanvis universitaris i beques de residència d'artistes i es va arribar a concretar la publicació d'una història de la literatura brasilera a càrrec de Manuel Bandeira (cosí de Cabral de Melo) o d'una antologia de la poesia brasilera actual a càrrec de l'acadèmic i poeta Múcio Leão. Darrere d'aquests acords hi destaca la intervenció del conseller cultural de

modo de ser y de vivir, y que representa, no una cosa estática y yacente, no una mera agrupación de pueblos, sino una corriente viva que atraviesa la Historia con una dirección y un rumbo providenciales» (Instituto de Estudios Hispánicos 1948, 12). Per a una anàlisi històrica i crítica d'aquest organisme, vegeu Delgado (1988), especialment, les pàgines 149-161, i per a una anàlisi de la seva política editorial, vegeu Delgado 2003. Darrerament, se n'han fet judicis equívocs, que emfasitzen la (suposada) imponderable collaboració d'intellectuals (Plata 2018, 20-23).

8 Ramon Rogent va fer estades a Portugal el 1945 i el 1947. Lisboa, pel context bèllic europeu, era refugi de fortunes, alguns colleccionistes d'art. L'obra de Rogent, però, va acabar a Rio de Janeiro. Això no obstant, el que m’interessa ara de ressaltar és que Portugal era vist com un pas previ a Amèrica i concretament al Brasil, com el mateix Rogent va reconèixer: «l'art portuguès contemporani és pont entre Europa i Amèrica: tramet al nou món el llatinisme - al qual pertany doblement com a país mariner-, i rep de l'altra banda la sensibilitat verge de gents noves». I acaba concloent: «Portugal demana - i ens demana, per tant - la síntesi europea que encara ha de venir i fructificarà qui sap on» (Vallès 2000, 114). 
l'ambaixada brasilera a Madrid, Renato de Mendonça, que anirà adquirint més protagonisme. ${ }^{9} \mathrm{El}$ cos diplomàtic del país americà, alguns d'ells influents creadors i intellectuals, assumirà uns objectius de divulgació cultural força inusitats en el panorama de les relacions internacionals d'aquest període. Així mateix, el flux migratori de catalans al Brasil, una migració eminentment econòmica i molt orientada a l'àrea de São Paulo, va augmentar exponencialment durant la dècada dels cinquanta. I, entre aquest contingent de catalans, també hi figuraven quadres de creadors que van dinamitzar la cultura brasilera d'aquells anys.

Intellectuals al servei del règim franquista van promoure a través de l'Instituto de Cultura Hispánica una política d'internacionalització que va tenir el seu efecte en la configuració cultural i política de tot l'Estat. En el marc teòric (i propagandístic) de la hispanitat, es van organitzar, per exemple, en la dècada dels cinquanta les Biennals Hispanoamericanes. Es desenvolupa en aquells anys una campanya de difusió de l'anomenat "arte nuevo". Noms tan poc afectes al franquisme com Pablo Picasso, Joan Miró o Wifredo Lam van ser elogiats des del règim pel seu indeliberat hispanisme. L'abstracte irromp en l'art oficial amb l'aplaudiment (i imaginem que també la perplexitat) dels jerarques del règim. La primera $\mathrm{Bi}$ ennal Hispanoamericana es va celebrar a Madrid (entre 1951 i 1952); la segona, a l'Havana (1954), i la tercera, a Barcelona (entre 1955 i 1956). En l'edició barcelonina es consagren els pintors més destacats de Dau al Set i se certifica l'èxit de la política cultural duta a terme pel règim franquista, en la mesura que va aconseguir trencar l'aïllament a què s'havia sotmès la creació dins de les fronteres de l'Estat a causa de la Guerra Civil. En un marc de relacions bilaterals, que s'haurien d'estudiar amb més detall, podem observar com el Govern brasiler va emprendre una sèrie d'accions per collaborar amb aquesta política d'internalització de l'art espanyol. ${ }^{10}$

9 Vegeu «Los acuerdos comerciales y culturales que se estudian con el Brasil», La Vanguardia Española, 30 ag. 1949. Renato de Mendonça, el gener del 1952, va impartir a Madrid el curs «Brasil moderno y sus orígenes, 1850-1950", organitzat per l'Instituto de Cultura Hispánica; vegeu La Vanguardia Española, 22 gen. 1952.

10 En aquest sentit, per exemple, el Ministeri d'Instrucció Pública del Brasil va atorgar en bloc un premi al VIII Saló d'Octubre, que estava integrat en la III Biennal Hispanoamericana, celebrada a Barcelona el 1955. Per a una valoració del paper de l'Instituto de Estudios Hispánicos en la propaganda i modernització de l'art espanyol, vegeu Marzo (2007, 37-45). 
Francisco Matarazzo Sobrinho, entre moltes altres coses fundador del Museu d'Art Modern de São Paulo (MAC / USP) i gran artífex de la Biennal de São Paulo, va tractar des d'un inici d'establir relacions de cara a una implicació oficial espanyola en l'incipient certamen artístic. Gràcies a la tesi de Cabañas Bravo (1991) sabem que Ciccilio Matarazzo havia començat una sèrie de contactes ja el 1951 per fonamentar una presència important de la pintura espanyola a la primera Biennal de São Paulo. Enric Tormo va revelar que el crític va arribar a Barcelona amb la voluntat de reclutar creadors per anar al Brasil. ${ }^{11}$ L'estat franquista no va participar oficialment en la primera, però en la segona Biennal paulista, Matarazzo va fer gestions diplomàtiques al més alt nivell perquè hi fos present $\mathrm{i}$, en un inici, volia que aquesta representació es vehiculés a l'entorn de la figura de Joan Miró (Cabañas 1991, 408). Finalment, el pintor va declinar la invitació (tampoc Dalí no hi va ser present). Tanmateix, la segona Biennal de São Paulo (1953), també coneguda com la Biennal del Guernica, va tenir un destacat color hispànic, encara que no sempre oficiós. En efecte, fora del pavelló espanyol oficial, aquesta cèlebre obra de Picasso va ser exposada i acompanyada d'altres setanta-quatre obres de l'artista malagueny. Ja un any abans, el 1952, el Ministeri d'Assumptes Exteriors havia decidit atorgar la responsabilitat de la delegació espanyola a l'Instituto de Cultura Hispánica, que va nomenar com a comissari Juan Ramón Masoliver. ${ }^{12}$ Masoliver va triar una nodrida representació catalana en la secció competitiva: Antoni Tàpies, Salvador Aulèstia o Ramon Rogent, o també la barcelonina Isabel Pons, que s'acabarà establint al Brasil. Va ser premiat Antoni Tàpies, malgrat que sovint el pintor n’ometria aquesta participació (Torre 2007). Crítics brasilers van contactar amb Joan Miró a París, com el mateix Francisco Ciccillo Matarazzo Sobrinho o Mário Pedrosa. Coneixem la carta que Miró va adreçar a Matarazzo l'11 de novembre de 1953

11 En l'entrevista que va fer Alessandra de Carvalho a Enric Tormo, li explica l'encontre que va tenir en un vaixell brasiler amarrat al port de Barcelona amb el crític brasiler, en presència de Cabral de Melo, durant el qual el pretenien convèncer de traslladar el seu taller d'impressor al Brasil (Carvalho 2014, 430-431).

12 Masoliver, a banda de São Paulo, va visitar Rio de Janeiro el 1953. Convidat per l'agregat cultural de l'Ambaixada espanyola, Manuel Viñolas, es va reunir amb els poetes Carlos Drummond de Andrade, Cecília Meireles, Augusto Federico Schmidt i Murilo Mendes, que és, pràcticament, la mateixa plèiade de poetes que havia antologat a Barcelona Alfonso Pintó el 1949; vegeu infra. 
i que va obrir les portes a Joan Ponç al món artístic brasiler. ${ }^{13}$ Ponç, sens dubte, és el cas més llampant de les relacions entre la pintura catalana i la brasilera. Però, en aquest cas, també hi ha un reduccionisme obvi. En aquest mateix període hi ha un nombre important $\mathrm{i}$ qualificat de pintors catalans a São Paulo: Francesc Domingo, Pere Tort, Ricard Rubio, Jaume González Bover o personatges que tenien (i tindran) una incidència cultural remarcable, com Víctor Castells o Salvador Riera o el ja esmentat Manuel Segalà, a Rio de Janeiro.

La poesia brasilera emergeix durant la postguerra de mica en mica en revistes i en antologies, no només a Barcelona, també a Madrid i a d'altres poblacions espanyoles. Ja el 1948 Ricardo Molina, en el número 5 de la revista cordovesa que dirigia, Cántico, havia fet conèixer versions dels poetes brasilers Augusto F. Schmidt, Ribeiro Couto, Carlos Drummond de Andrade i Mário de Andrade. Certament, l'estada de Cabral de Melo a Barcelona en podia haver facilitat la mediació. Però més enllà del paper important de mitjancer, es caracteritza pel paper d'interventor dins de la cultura catalana del moment. El llavors jove diplomàtic no es va estar d'adoctrinar políticament i estètica una elit intellectual i de participar activament en iniciatives concretes, tant en aspectes puntuals de la cultura brasilera com de l'espanyola o catalana. En aquest curt i intens període barceloní de Cabral de Melo comptem, per exemple, amb la destacadíssima monografia que va escriure sobre Joan Miró - pintor que coneix a través de Ramon Rogent-, les traduccions de poetes catalans aparegudes a São Paulo el 1949 o les de Carles Riba, algunes editades a la revista

13 «Je me permets de vous présenter mon ami le peintre espagnol Joan Ponç, très doué et très travailleur. Il compte s'installer a São Paulo, je vous serai reconnaissant si vous lui donnez des idées pour s'orienter un peu», Arquivos da Fundação Bienal de São Paulo. Joan Ponç, en el seu relat autobiogràfic, assenyala que el 1953, en viatge de lluna de mel a París, visita Miró i és ell qui li dona l'empenta decisiva per embarcar-se rumb a l'Amèrica del Sud: «Efectivamente, al despedirme, me dio valiosísimas cartas que me abrieron las puertas como por arte de magia. Con muchos dibujos, poco dinero e infinita esperanza en una humanidad más pura, me voy al Brasil» (Omer 1972, 248). Segons Ponç, és Miró, i no Cabral de Melo, el responsable de la seva decisió, com ell mateix es va preocupar d'aclarir. Maite Torroella, en la valuosa entrevista que li va fer Alessandra Carvalho, afegeix detalls sobre la sintonia personal entre Ponç i el llavors cònsol general del Brasil i poeta Raul Bopp, i també amb Matarazzo, que el convencen de marxar al Brasil (Carvalho 2014, 486-487). 
Ariel. ${ }^{14}$ Activitats totes elles importants i relativament insòlites en la seva trajectòria literària pel fet que Cabral de Melo no tindrà més endavant una dedicació destacada ni en la crítica d'art ni en la traducció. Cal, potser, situar aquest conjunt d'iniciatives en un entramat de relacions que facin més entenedora tota aquesta activitat.

El diplomàtic brasiler, tot just arribat a Barcelona, sembla clar que tenia entre les seves principals prioritats editar una revista. Per la correspondència servada d'aquells anys sabem el nom inicial d'aquest projecte, Antologia, i la divisa de Paul Valéry que l'havia de guiar: "plus élire que lire». Els continguts del primer número, segons va fer saber per carta a Manuel Bandeira, ja estaven gairebé decidits: un assaig sobre el vocabulari de la poesia de Drummond de Andrade, un altre sobre l'alexandrí en la poesia castellana del moment $\mathrm{i}$ « 25 tankas de Carles Riba, o melhor poeta catalão vivo, traduzidas por mim.» Era, doncs, la intenció de la revista completar el ventall poètic iberoromànic. El seu director es reservava la traducció dels únics textos literaris que hi havia previst publicar: els de Carles Riba, no només perquè el considerava el millor entre els catalans, sinó de ben segur també perquè era amb qui se sentia més proper estèticament. Ens consta que Cabral de Melo va conèixer el poeta català. Li va regalar un dels rars exemplars de Psicologia da Composição — només en va fer una tirada de quinze el desembre del 1947-, actualment a la Biblioteca de Catalunya. Pocs mesos després, a la revista Ariel apareixen tres tankes de Riba traduïdes per Cabral i acompanyades d'una nota breu, que hem d'atribuir a Joan Triadú. ${ }^{15}$

A la correspondència amb la cèlebre escriptora Clarice Lispector, de començament de l'any 1949, Cabral de Melo la informava del seu propò-

14 João Cabral de Melo, Joan Miró (Barcelona: Edicions de l'Oc, 1950). Vegeu també la traducció catalana i l'original portuguès, acompanyat de diversos treballs crítics a Neto 2008. Pel que fa a la feina de traductor des del català, disposem del treball de Ramon Farrés (2017), en què es destaca, entre d'altres elements, l'existència de traduccions de poesia catalana de Cabral de Melo que van quedar al calaix. I, des de la perspectiva brasilera, esmento el treball de Ricardo Souza de Carvalho (2009). Les traduccions del català de Cabral de Melo publicades a Revista Brasileira de Poesia (1949) són ara disponibles a Neto (2010).

15 «Joâo Cabral ha imprès personalment i a casa seva, el seu llibre de versos Psicologia de composiçâo, on aprofundeix cap a la personalitat del poeta amb una nítida austeritat d'expressió i un lirisme que es manté en la línia de les proximitats Guillén-Riba i, en certa manera, Valéry» (Triadú 1948, 40). 
sit de crear una revista clandestina de literatura catalana i brasilera que havia de ser continuadora de la llavors recentment clausurada per les autoritats franquistes, Poesia, dirigida per Palau i Fabre. ${ }^{16}$ Finalment Cabral de Melo va estampar en la seva Minerva un únic número de la revista $O$ Cavalo de Todas as Cores el gener del 1950. Al davant d'aquesta iniciativa, com a codirector de la publicació, hi figurava Alberto de Serpa. ${ }^{17}$ Va ser per mediació del poeta portuguès que hi van participar dos compatriotes seus: José Régio i Pedro Homem de Mello, tots dos d'una significada orientació catòlica. En definitiva, O Cavalo de Todas as Cores no és el testimoni nítid de la poètica cabraliana, però sí que ens mostra una continuïtat evident amb la connexió lusitana d'Entregas de Poesía. S'incloïa la versió castellana de Vinícius de Moraes a càrrec d’Alfonso Pintó, un dels collaboradors en primera instància més propers a Cabral de Melo i que, en aquell moment concret, centralitzava bona part de la mediació entre el Brasil i Espanya. I també cal destacar un altre nom de pes entre els participants barcelonins: Rafael Santos Torroella. Va ser ell qui va incorporar Cabral de Melo a l'aventura de Cobalto i que assumirà aviat un paper important en la divulgació de la poesia brasilera. A través de Santos, Antoni Tàpies va fer la coneixença de Cabral i el brasiler va presentar l'exposició «Un aspecto de la joven pintura. Tàpies, Cuixart, Ponç» a l'Institut Francès

16 Cabral de Melo escrivia des de Barcelona (15 de febrer de 1949) a Clarice Lispector, casada amb el diplomàtic destinat a Berna Maury Gurgel Valente: «Ando, por mim, numa enorme preguiça. Tenho planejada agora, com alguns amigos catalães, uma revista clandestina catalã brasileira. Não sei bem como será. Mas desde que a polícia fechou a que eles publicavam aqui, quero fazer alguma coisa de propaganda da cultura deles junto aos intelectuais brasileiros. Farei de Vocês destinatários obrigatórios da coisa» (Sousa 2000, 295). Segons Ricardo Souza de Carvalho, «a revista proibida chamava-se Algol, que conheceu um único número no final de 1946, dirigida por Joan Brossa, Arnau Puig e Antonio Tàpies. Esses jovens, mais Modesto Cuixart, Joan Ponç, Joan-Josep Tharrats e Juan Eduardo Cirlot, criaram em 1948 a revista Dau al Set, nome pelo qual ficou conhecido esse grupo de artistas de vanguarda, um dos mais importantes do pós-guerra na Espanha» (Carvalho 2007, 114). Algol, en efecte, només va tenir un número, però el 1947. Gairebé segur que Cabral es refereix a la revista de Josep Palau i Fabre Poesia (1944-1945) — aquesta, sí, clandestina.

17 El sumari de la revista, de gener del 1950, incloïa: Pedro Homem de Mello, «Nove canções católicas»; Vinícius de Moraes, «A Bomba atômica»; Rafael Santos Torroella, «Cuatro poetas»; José Régio, «Poesia», i Enric Tormo, «Xilografia popular en Cataluña». La portada va ser a càrrec de Garcia Vilella i representava un cavall alat. Arnau Puig, en una monografia dedicada precisament a Garcia Vilella, n’evoca la relació amb Cabral de Melo (Puig 2004, 11-12 i 19) i cal tenir-ne encara present una evocació anterior (Puig 1980). 
de Barcelona (13 de desembre de 1949 - 3 de gener de 1950). Tots els testimonis apunten, doncs, que va ser per mediació de Santos Torroella que Cabral entra en contacte amb els integrants de la revista Dau al Set. Tanmateix, gosaria dir que l'interlocutor més proper a Cabral de Melo en la seva etapa barcelonina va ser Enric Tormo, amb qui va compartir l'ofici —i la dèria- d'impressor i gravador.

D'Alfonso Pintó n'he extret fogonades que a penes ens fan entreveure escenaris de la cultura barcelonina durant fonamentalment la dècada dels cinquanta i començament dels seixanta. Un període frontissa en què les hegemonies polítiques, nacionals o estètiques no estaven tan marcades com en anys posteriors o com la historiografia sol assenyalar. És l'etapa en què s'inicien creadors que no van participar com a adults en la Guerra Civil, quadres que generalment ja s'havien format en el sistema educatiu feixista. El nom d'Alfonso Pintó és present en les aproximacions a la poesia barcelonina en castellà de postguerra. Companys de generació l'esmenten entre revistes, editorials o tertúlies, sempre de passada. També en la premsa de l'època resseguim rastres de la seva activitat personal als «Ecos de Sociedad» de La Vanguardia Española. Les felicitacions per la seva onomàstica o l'anunci del seu retorn d'una estada al Montseny ens configuren la imatge d'un jove de bona família en la Barcelona de l'estraperlo i del racionament. Alfonso Pintó López-Pelegrín va néixer a Madrid el 27 d'agost de 1924 en el si d'una nissaga de destacat protagonisme a l'Espanya liberal del segle XIX. Amb la seva família es va establir a Barcelona, on va cursar els estudis de Filosofia i Lletres entre 1944 i 1949. Potser va tenir l'oportunitat d'entrar en contacte amb la literatura brasilera i, en concret, amb João Cabral de Melo, perquè el poeta brasiler havia acceptat de fer unes classes introductòries de la literatura del seu país a la Universitat de Barcelona. ${ }^{8}$

18 A la tesi d'Alexandra Vargas de Carvalho es recull el testimoni de Cabral de Melo. Com el poeta mateix va explicar per carta a Lêdo Ivo, va ser convidat a la Universitat de Barcelona, concretament a la secció de Romàniques, perquè fes una introducció de la literatura brasilera: «Fui convidado para dar um curso de literatura brasileira na Faculdade de Filosofia e Letras da Universidade de Barcelona. Já o comecei — considerando que o curso estava no pré, resolvi empezar pelo modernismo-e assim é que, já há dias, os alunos de filologia românica da Universidade (fundada em 1400 + ou menos) muito sérios, anotam nomes de pessoas assim: Lêdo Ivo, Antônio Rangel Bandeira, Clarice Lis- 
Segurament, la millor aproximació a Alfonso Pintó la devem als treballs de Dolores Manjón (2007 i 2008) sobre els poetes en castellà de la Barcelona de la postguerra. La seva tesi se centra en poetes nascuts entre la franja del 1911 i el 1922, llevat d'Alfonso Pintó, que va néixer el 1924. És significativa aquesta excepció en la mesura que inclou aquest poeta dins el grup en què es van donar a conèixer majoritàriament a la immediata postguerra, quan de fet, per estricta cronologia, Pintó hauria de ser en el grup que gravitava a l'entorn de Dau al Set o entre els poetes de l'Escola de Barcelona. Tanmateix aquesta inclusió de Pintó entre poetes més grans ja l'havíem trobat en Masoliver (1994, 428-442), que, en parlar d'Entregas de Poesía, l'esmenta com si hi hagués participat. $\mathrm{O}$, anteriorment, en Valbuena Prat, que agrupa Pintó entre els poetes de tendència surrealista al costat de Juan Eduardo Cirlot, Francisco Mayáns, Julio Garcés, Manuel Segalà i José Miguel Velloso. En aquests relats, Barcelona és ja presentada, com no ho havia estat mai en l'Espanya contemporània, com a plaça significant de la lírica hispànica. Ben aviat Ángel Vallbuena Prat reconeixerà l'existència d'«El grupo catalán de la Posguerra» (Vallbuena 1968, 974-977).

Alfonso Pintó va participar en l'Instituto de Estudios Hispánicos, on es congregaven els representants de la vida cultural «oficial pero inquieta (no es un oxímoron), de la Barcelona del tiempo» (Amat 2005, 297). Entre les seccions d'aquest Instituto figurava el Seminario Juan Boscán, fundat per Francesc Galí el 1948, el qual es marcava entre els seus objectius establir llaços amb la més renovada poesia hispanoamericana. ${ }^{19}$ Pintó va pronunciar una conferència sobre poesia brasilera el 16 d'abril de 1953, acompanyat pel llavors cònsol general del Brasil, el poeta Raul Bopp. ${ }^{20} \mathrm{La}$ hispanitat era entesa, doncs, en un registre deliberadament vague, que

\footnotetext{
pector etc. Porque ainda não desencaixotei meus livros, não me foi possível ainda fazê-los ler o que esses nomes escrevem» (Carvalho 2014, 31).

19 Per a una valoració de l'Instituto de Estudios Hispánicos i del Seminario Boscán, intuïm que des del testimoni directe de Josep M. Castellet, cal tenir present l'aportació de Teresa Muñoz, en què es pot seguir el tramat de relacions polítiques i culturals entre Barcelona i Madrid, per una banda, i entre Espanya i Amèrica, per l'altra (Muñoz 2006, 84-90).

20 Alexandre Cirici Pellicer també parla de les trobades a l'Instituto de Estudios Hispánicos a Madrid a començament del 1961, a les quals assisteixen Santos Torroella, Joan Cortés i Gregorio Prieto (un artista a qui Alfonso Pintó dedicarà un poema). En aquesta trobada també hi participen brasilers: F. dos Santos Trigueiros, del Museu de Monodes, i Mário Barata (Cirici 2014, 436-437).
} 
pretenia atorgar un aspecte de normalitat fins i tot a allò que estava sotmès a la més iniqua anomalia, com era el cas de la literatura catalana. Devem també a Alfonso Pintó les traduccions en revistes poètiques espanyoles (Cántico de Còrdova o Ámbito de Saragossa) de poetes catalans com Vinyoli, Palau, Perucho, Triadú o J.V. Foix.

Cal recordar que Fernando Gutiérrez, nebot de Luys de Santa Marina, va signar — de fet, Josep Pedreira en va ser el responsable - una extensa antologia: La poesia catalana. Els contemporanis (Barcelona: José Janés, 1947), un volum en molts aspectes interessant —i que malauradament no ha estat prou ponderat-, que es podria incloure en aquesta operació de «normalització» hispànica. Sens dubte, una de les fites més assenyalades d'aquesta operació van ser els congressos de poesia. En aquests esdeveniments es van trobar personalment molts d'aquests agents que operaven des de diversos indrets peninsulars i des de diverses posicions estètiques, polítiques i personals. La presència significada de poetes catalans ha disposat i disposa d'una nodrida bibliografia. Sembla que darrere d'aquest èxit de l'organització hi va haver la feina de Dionisio Ridruejo i de Rafael Santos Torroella, secretari dels congressos. És oportú recordar que la representació portuguesa també hi fou requerida pels organitzadors. Després de diverses vacillacions, finalment, Alberto de Serpa es va decidir a participar en el primer congrés a Segòvia, el 1952. El mateix poeta va descriure la seva experiència, que serveix també per identificar quina recepció es feia llavors de la cultura portuguesa. Un dels primers interlocutors, si no el primer, va ser el secretari del congrés, Rafael Santos Torroella, collaborador de Serpa de quan dirigia, amb Cabral de Melo, la revista $O$ Cavalo de Todas as Cores. ${ }^{21}$

La primera publicació d'Alfonso Pintó és el poemari Corazón en la tierra, imprès el 1948 en un tiratge de 100 exemplars per João Cabral de Melo. Es tracta del volum que inicia la llegendària collecció «El Libro Inconsútil», per bé que Cabral de Melo ja havia editat diverses plaguetes a Barcelona

21 «À entrada do hotel, um abraço do Rafael Santos Torroella —o secretário do Congresso, meu colaborador d'O Cavalo de todas as cores, alto, forte, moreno, animado- dá-me logo confiança» (Serpa 1952, 7). 
en llengua portuguesa i sense el segell de la collecció. ${ }^{22}$ Tant per la forma com pel contingut, l'influx surrealista de Corazón en la tierra sembla indefugible com van ressenyar els cronistes de l'època: «poesía briosamente superrealista cuya intensidad recuerda a la de Paul Éluard» (Cántico $1948-1949,126) .{ }^{23}$

També dins d'«El Libro Inconsútil», l'any 1949, Alfonso Pintó publica l'Antología de poetas brasileños de ahora. Primera Serie. Es tracta de cinc plaguetes sense relligar amb una sobrecoberta que duu el títol que acabo d'esmentar i amb el següent colofó: «Esta edición consta de 120 ejemplares en papel de hilo verjurado, João Cabral de Melo, impresor.» A les cinc cobertes respectives només hi ha la indicació de cadascun dels cinc poetes triats, que són Carlos Drummond de Andrade, Vinícius de Moraes, Augusto Federico Schmidt, Cecília Meireles i Murilo Mendes. ${ }^{24}$ No es pot dir que sigui una tria original. Tots aquests poetes ja havien estat introduïts en revistes espanyoles. Tanmateix, s'entreveu un cànon líric en què segurament trobem a faltar les veus més trencadores de l'avantguarda brasilera. L'impacte d'aquestes traduccions va ser certament escàs. Algunes revistes literàries de l'època en van acusar recepció i José Luis Cano, des d'Ínsula — publicació en què Pintó collaborava escadusserament - en va fer una

22 L'exemplar que he pogut consultar a la Biblioteca de Catalunya va dedicat al seu antic propietari i company de generació, Nèstor Luján. Vegeu una relació completa i detallada dels llibres i plaguetes editades per Cabral de Melo durant el primer període barceloní a Carvalho (2014, 428-429). El següent volum de la collecció «El Libro Inconsútil» és el poemari de Joan Ruiz Calonja, Alma a la luna, també del 1948. Tal vegada Ruiz Calonja i Pintó podien haver coincidit en la mateixa promoció a la universitat. Per una targeta personal que es troba en el volum Corazón en la tierra, adreçada al seu antic propietari, Nèstor Luján, sabem que el domicili de Pintó era al carrer de Muntaner, 439, 2n 1a, a prop, doncs, de la residència de Cabral de Melo a Barcelona, que després ho va ser de Santos Torroella, també al carrer de Muntaner, 448, 3r 4a.

23 Potser l'obra de Pintó que suscita més interès sigui l'assaig La targeta postal. Estética e historia (Barcelona: PEN, 1953). La reivindicació del kitsch a través d'una de seves expressions més reputades, la postal, el connectava, per exemple, amb el Dalí de just abans de la guerra. Aquest assaig feia ressaltar el trait d'union que havia establert el surrealisme amb el modern style i que tant rendiment assoliria en les dècades següents.

24 Les versions en espanyol són les següents: de Carlos Drummond de Andrade, «Residuo» $\mathrm{i}$ «Estancias»; de Vinícius de Moraes, «Elegía» i «Al primer amigo»; d’Augusto Frederico Schmidt, «La vuelta del hijo pródigo»; de Murilo Mendes, «Ventanas del caos», i de Cecília Meireles, «Seis canciones», l'última de les quals: «Contigo, Antonio, Antonio Machado, / contigo quisiera pasear...». 
breu ressenya. ${ }^{25}$ Aquesta traducció obre una sèrie d'altres que aniran ampliant el repertori de poetes brasilers a l'abast del públic espanyol. Però potser són les dues edicions del poema dramàtic Cobra Norato de Raul Bopp el cas que singularitza més Alfonso Pintó i la seva relació amb la poesia brasilera. Aquestes dues edicions (i no traduccions) del 1952 i del 1954 van sortir amb el segell de Dau al Set i van anar acompanyades, la primera, amb una coberta de Joan Ponç i, la segona, amb un dibuix de Joan Miró. ${ }^{26}$

En aquest mateix període, des de Madrid, i generalment amb un suport institucional, es van anar publicant antologies que pretenien afinar una panoràmica de la poesia brasilera. El 1948 havia aparegut una selecció a càrrec d'Osvaldo Orico precedida d'una «Breve Introducción al estudio

25 «En esta bella antología de poetas brasileños actuales, el traductor, Alfonso Pintó, nos presenta a cinco poetas del Brasil, muy poco conocidos del lector español: Murilo Mendes, Carlos Drummond de Andrade, Cecília Meireles, Augusto Federico Schmidt y Vinícius de Moraes. Las piezas que Alfonso Pintó ha seleccionado de estos poetas nos muestran que la poesía brasileña está quizá a la cabeza de la poesía latinoamericana. Sólo la argentina o la chilena podrían oponérseles. De Murilo Mendes traduce Pintó el poema "Ventana al caos", de influencia surrealista, y en la que el impacto de la guerra parece haber dejado su huella en su desgarro. Hay en el verso de Mendes esa "harmonía del terror" que él mismo canta junto a esos "pájaros galopando clemencias". Las imágenes de Mendes son sangrantes y luminosas. De Carlos Drummond de Andrade se traducen dos poemas. Residuos y Estancias, en los que palpita una gran ternura por las cosas y una auténtica emoción de amor. Las seis canciones de Cecília Meireles son aladas y gráciles, como uno se imagina a su autora. Pero una de ellas, la que dirige a nuestro Antonio Machado, es la que nos conmueve. He aquí sus primeros versos: "Contigo, Antonio, Antonio Machado / contigo quisiera pasear, / por mañana de sierra, noche de río / o nacimiento lunar". El poema "La vuelta del hijo pródigo", de Augusto Federico Schmitd, el menos moderno de la selección, entra en una línea tradicional, pero llena de nobleza y de auténtica emoción. Su tono, sin embargo, contrasta con el resto de la antología. Finalmente, Vinícius de Moraes, con su deliciosa "Elegía al primer amigo", nos revela a un poeta de gran delicadeza y de verso trémulo y misterioso. Muy bellas las traducciones de Alfonso Pintó, y exquisita la presentación del libro, al cuidado de su editor, João Cabral de Melo. Una breve noticia sobre los poetas incluidos quizá habría sido oportuna» (Cano 1949, 5). El mateix Cano, pocs anys després, tornarà a fer referència a aquesta «preciosa edición», per bé que «se estropee con numerosas erratas» (Cano 1962, 120).

26 També el 1952 apareix per primera vegada una traducció de Bopp a l'espanyol: «Tapuia (hija de blanco e india)» a càrrec de l'uruguaià, i destacat estudiós de la cultura afroamericana, Ildefonso Pereda Valdés a la revista mallorquina Dabo 7 (1952): 11-12. En aquesta revista hi va participar Alfonso Pintó o Rafael Santos Torroella, que va publicar un poema de Carlos Drummond d'Andrade i també un de seu de resposta. El poema de Carlos Drummond d'Andrade és «Uma noite que súbito», amb la dedicatòria explícita «A Rafael Santos Torroella» i datat a «Rio de Janeiro, Fevreiro 1953». El del poeta català, «Tú, de duros brasiles minerales», és datat a «Barcelona, abril 1953». Vegeu Dabo 16 (1955): 10-11. Val la pena afegir que Alfonso Pintó publicarà un altre poemari, La Paz y otros poemas (Barcelona: Dau al Set, 1952), amb una coberta d'Antoni Tàpies. Certament, pocs poetes han tingut el privilegi que Ponç, Miró i Tàpies hagin collaborat amb les seves publicacions. 
de la Literatura». Aquesta antologia, apadrinada per Dámaso Alonso, es tanca amb els poetes nascuts al final del segle XIX, concretament amb Jorge de Lima i Raul Bopp, tots dos del 1898. El 1950 a Madrid s'editarà una antologia dels tres poetes brasilers més difosos, Bandeira-DrummondSchmidt, amb la intervenció de la lusitanista Pilar Vázquez Cuesta. I dins de la collecció «Adonais», Rafael Santos Torroella publicarà una antologia de Carlos Drummond de Andrade el 1951, el primer poeta brasiler editat en una monografia. ${ }^{27}$ Segons l'antòleg: «Carlos Drummond de Andrade es, por su profundidad, su elevación, su autenticidad, acaso el más alto poeta de toda la lírica brasileña, tan nutrida hoy de nombres y de obras ejemplares» (Santos 1951, 14). En aquest cas concret, sí que aviat es va detectar la influència d'aquest poeta brasiler en la jove poesia espanyola..$^{28}$

Drummond era també un poeta molt vinculat a la política del president Getúlio Vargas i a la voluntat renovadora cultural que tenia el Govern brasiler amb noms com Le Corbusier i Oscar Niemayer — tots uns aires de transformació que van quedar estroncats amb el suïcidi del president el 24 d'agost de 1954, que va deixar la política brasilera en un estat de commoció del qual va trigar molts anys a recuperar-se.

Tanmateix, destaca entre les publicacions del moment que van voler donar a conèixer la poesia d'aquest país americà l'Antología de la poesía brasileña (1952), signada pel conseller cultural de l'ambaixada brasilera a Madrid, Renato de Mendonça, i amb el segell de l'Instituto de Cultura Hispánica. Aquest volum es pot considerar una fita des de molts punts de vista i alhora també ens mostra les limitacions d'un escenari de recepció

27 Osvaldo Orico, Poetas del Brasil (Madrid: Ediciones de Cuaderno de Literatura / Instituto Miguel de Cervantes / CSIC, 1948); Bandeira-Drummond-Schmidt. Tres poetas del Brasil, a càrrec de Pilar Vázquez Cuesta amb la collaboració de Leónidas i Vicente Sobrino Porto (Madrid: Artes Gráficas Evaristo San Miguel, 1950), i Carlos Drummond de Andrade, Poemas, introducció i traducció a càrrec de Rafael Santos Torroella, Adonais LXXIII (Madrid: Rialp, 1951).

28 José Luís Cano en va dir: «En alguna ocasión he señalado mi impresión, no sé si errónea, de que estas versiones castellanas de Drummond han influido en uno de los mejores poetas españoles de la nueva generación, José Ángel Valente, concretamente en su primer libro, A modo de esperanza, también aparecido en la Colección Adonais» (Cano 1962, 121). El jove Valente va reconèixer la influència de Drummond en la recerca d'una veu poètica que procurava la dissolució del particular en allò social. Un programa, el del realisme social, que aviat Valente abandonarà. Tanmateix, val la pena recordar que un poeta barceloní, José Agustín Goytisolo, va establir anys més tard un contacte directe amb Drummond, que es testimonia en la seva poesia (Santos 2012). 
excessivament oficiós. Es tracta d'una antologia composta de dues parts: la primera correspondria a la tradició que, des del romanticisme, arriba a les poètiques simbolistes fin-de-siècle; la segona se centra en poetes del segle Xx. Els traductors al castellà són escriptors que havien coincidit en la revista madrilenya El Espectador de las Artes y las Letras: Rafael Morales, encarregat de la primera part (el primer traductor de Pessoa a la postguerra), i Rafael Santos Torroella. Una de les aportacions més importants d'aquesta antologia és l'entronització de Cabral de Melo com una de les veus imprescindibles de la nova poesia brasilera. Hi és representat amb O cão sem plumas, O engenheiro i fragments de Psicologia da Composição. En el davantal de presentació es diu que l'intellectualisme cabralià s'ha orientat cap una recerca social compromesa amb la realitat, una consigna que Santos Torroella pretenia traslladar a la poesia espanyola i catalana. Tanmateix, l'oficialisme de la publicació no estimula precisament la ruptura. El seu caràcter compendiós, de resum de tota la poesia brasilera contemporània, tampoc no afavoreix la singularitat de l'aportació de Cabral, que queda aigualida entre tants noms. ${ }^{29}$

$\mathrm{Al}$ final de la dècada dels cinquanta es pot constatar que la internacionalització de la cultura del Brasil sembla imparable. La canairinha de Pelé, o Rei, havia guanyat el campionat del món de futbol el 1958, un èxit esportiu que va cohesionar una forta identitat nacional que es projectava arreu. El film Orfeu negro aconseguia la Palma d'Or de Canes el 1959 i Vinícius de Moraes passava a ser el poeta i la veu de la bossa nova. Amb Vinícius, Tom Jobim o João Gilberto, la música popular brasilera adquiria proporcions de fenomen global.

29 De Cabral de Melo se’ns diu: «Su violín de Ingres son las artes gráficas, y en su impremta "portátil” de propiedad editó durante su estancia en España una serie de libritos bajo la rúbrica de O livro inconsútil [...] su poesía ha aportado a la lírica brasileña actual un elemento intelectualista; hoy se esfuerza, sin abandonar este último, en lograr una expresión más amplia y profundamente humana, de contenido social. De gran agudeza crítica en las artes plásticas, recientemente ha publicado uno de los estudios más penetrantes que sobre Joan Miró se han escrito» (Mendonça 1952, 281). En aquesta Antología hi ha el poema «Mi patria», de Vinícius de Moraes, que es diu que va ser publicat per «El Libro Inconsútil» de Barcelona el 1948. A la mateixa antologia també hi ha un inèdit de Vinícius de Moraes, «Mensaje a la poesía». Per a una valoració del paper de l’Instituto de Cultura Hispánica en la promoció de la poesia en el context espanyol, vegeu Provencio (2003), en què s'esmenta l'antologia de Mendonça. 
A la dècada dels seixanta, el pol de recepció de la cultura brasilera a Espanya es va desplaçar gairebé completament a Madrid. Alfonso Pintó, installat a Berna, ja no tornarà a publicar cap altra traducció; Santos Torroella i Masoliver només faran referències esparses del país sud-americà sense cap aportació destacada, i els autors que van gravitar a l'entorn de Dau al Set es distanciaren de mica en mica dels contactes brasilers. A Madrid, destinat com a secretari de l'ambaixada, Cabral de Melo troba en Ángel Crespo l'home capaç d'irradiar en el medi cultural espanyol la novetat vinguda del Brasil. Sota el mantell protector de l'ambaixada, es crea la Revista de Cultura Brasileña, que en molts aspectes és la publicació que Cabral de Melo havia provat de tirar endavant a Barcelona i que a Madrid es consolida no només com a aparador de la cultura brasilera, sinó també com a motor de renovació de les poètiques hispàniques. La gran diferència és que Cabral de Melo ja no es posarà al davant d'aquesta iniciativa i delegarà la responsabilitat a Crespo. A través de les pàgines de la Revista Cultural Brasileña, entra, per exemple, el concretisme, presentat en bona mesura com a culminació de la poètica cabraliana, o es fa una apologia i una història de l'avantguarda brasilera com a punt de referència de la modernitat del segle xx. Tot això, és clar, amb les salutacions dels poetes oficiosos i acadèmics espanyols que veien sempre amb bons ulls la producció cultural d'un país llatinoamericà, expressió de la irreductible hispanitat. La Revista de Cultura Brasileña també és un exemple més de com l'influx internacional, sobretot el més inequívocament vinculat a l'avantguarda, es produïa en un context de debilitat d'una hegemonia cultural de l'Estat espanyol. Els instituts de cultura estrangera van influir en alt grau en la cultura espanyola del franquisme com segurament mai més tindran l'ocasió de fer-ho. I concretament el Brasil, amb el seu cos diplomàtic, demostrarà un potencial creatiu i disposarà d'una capacitat prescriptora insòlita en el marc de la política exterior cultural llatinoamericana. Barcelona haurà d'assumir un paper secundari, relegada a plaça consular. 


\section{El combat estètic}

contra todos os existencialismos, surrealismos, magicismos, negadores da realidade e do homem Carta de Cabral de Melo a Joan Brossa (veg. Apèndix, infra, c.1)

Un surrealisme innocu per al règim feixista era present a les revistes literàries d'arreu de l'Espanya del primer franquisme, tant a les oficialistes i oficioses com a les que no ho eren tant. El patriarca allitat de la poesia hispànica, l'acadèmic Vicente Aleixandre, expedia enhorabones també als més inquiets creadors enfebrats per les exploracions que podien semblar revoltes d'altres temps. En la Barcelona de postguerra, el surrealisme va tenir un paper important en tertúlies i revistes literàries, abans que, entre d'altres, el grup de Barcelona l'arraconés. A les arts plàstiques —és el cas de Dau al Set-, el component surrealista va ser molt notori. Creadors de la primera fornada avantguardista a Catalunya seran persistents testimonis o ombres protectores del renovament artístic a partir dels anys cinquanta. Josep M. de Sucre, J.V. Foix o Sebastià Gasch hi tenen un paper cabdal. Falta veure si són ruptura en els termes en què entendríem l'avantguarda: el d'una ruptura també social que desvelés l'engany de l'autonomia de l'art burgès. Més aviat el que hi havia era maintenance, l'exigida per uns temps que no estaven per a sortides de to, sense oblidar, però, que J.V. Foix ja havia situat la revolució, l'«evasió de la massa», fora de la seva poètica just abans de començar-la, l'any $1935^{3^{30}}$ I és des de la impertorbabilitat d'aquesta maintenance que els prohoms que abans de la guerra havien estat propers a les activitats de l'ADLAN, en ple franquisme, promouran una tímida recuperació de l'art d'avançada. Potser tot plegat mereixeria una reflexió que definís amb més claredat el surrealisme (o l'avantguarda en general) a Espanya. És innegable que durant el període republicà el

30 Per a Foix: «La revolució - les revolucions - materials, socials o polítiques són l'evasió de molts. La massa s'hi evadeix. Però el poeta és, de sempre, un evadit. De la realitat només —o solament, o especialment o estrictament - n'heu la màgia» (Foix 1935, 4). Utilitzo el concepte "maintenance" manllevat de l'assaig de Jean Paulhan, que es publicar l'any 1941, Les fleurs de Tarbes ou la Terreur dans les Lettres, en què descrivia les lletres franceses contemporànies com un camp de batalla entre la retòrica i el terror (és a dir, l'avantguarda). 
surrealisme més violent i la crítica més trencadora hi van ser, com també hi eren contrapesos que, sense desdenyar aquestes propostes, les situaven en un segon temps, sense arestes, en què es poguessin contemplar com un mer artefacte estètic; el pensament d'Ortega y Gasset hi era tothora present com la seva cauta posició d'espectador davant l'art d'avançada. Dalí i el dalinisme havien dimitit moralment, segons sentència d'André Breton, i havien passat a ocupar un espai vistós en l'aparell propagandístic franquista. El poeta com a evadit era una posició tal vegada inhibidora, intolerable per als que pretenien la rehumanització de l'art en la immediata postguerra. Tanmateix, no tot es pot reduir a una dicotomia moral tan injusta com irreal. L'«escala de l'evasió» va tenir molts replans, la complexitat dels quals, començant per Miró, ens exigeix rigor. ${ }^{31} \mathrm{El} \mathrm{juliol} \mathrm{del} \mathrm{1948,}$ el segon volum de Cobalto. Arte Antiguo y Moderno, impulsat per Santos Torroella, està dedicat íntegrament al surrealisme. L'any següent es constituiria Cobalto 49, al davant del qual hi havia el matrimoni Rafael Santos Torroella i María Teresa Bermejo, i un elenc de la vella guàrdia de l'ADLAN, amb Cabral de Melo entre molts d'altres. La constitució d'aquest grup no va ser exempta de tensions d'ordre polític, nacional i personal. ${ }^{22}$ Si no restringim l'atenció en la producció més prestigiada de Cobalto, del segell de Dau al Set o de l'exquisida collecció «O Livro Inconsútil» de Cabral de

31 Sobre això, vegeu el treball de Guigon (1992). És especialment pertinent la revisió que, segons Cabral, Miró havia fet del surrealisme. El seu abandó de l'automatisme psíquic, procediment característic dels surrealistes, el contraposa al treball intellectual i a la lluita per l'autèntic, que són, certament, claus intrepretatatives molt útils per entendre el gir poètic que el mateix Cabral de Melo pretenia imposar (Neto 2008, 56-57). La conferència que Cabral de Melo va pronunciar el 1952 i que es pot considerar l'assaig de la seva poètica, Poesia e composição, s'ha de llegir en parallel amb l'assaig sobre Miró. El poeta brasiler incideix en la importància del treball, en la creació del poema objectiu $i$ en el rebuig a qualsevol misticisme o arrebat irracional, condicions indispensables per a un compromís autèntic amb la raó i amb l'home: «Na origem da atitude que aceita o predomínio do trabalho de arte está muitas vezes o desgosto contra o vago e o irreal, contra o irracional e o inefável, contra qualquer passividade e qualquer misticismo, e muito de desgosto, também, contra o desgosto pelo homem e sua razão» (Neto 2003 $b$, 20).

32 Per a una valoració documentada, vegeu Vidal (1997). Vidal Oliveras diu que és el primer monogràfic sobre el surrealisme després de la guerra i fa una descripció de les principals aportacions de l'època. Vegeu també la tesi, que estudia el surrealisme i la poesia espanyola, de Manuel Duran Gili, «El superrealismo en la poesía española contemporánea» (Universidad Nacional Autónoma de México, 1950), un treball interessant per molts motius, entre altres, perquè és fet a l'exili i perquè Duran és capaç de traçar més continuïtats del surrealisme que discontinuïtats malgrat el sec que suposa la Guerra Civil. 
Melo, ens adonarem que es van fer obres de caràcter molt variat i no sempre arrenglerat a l'art d'avançada. El caràcter eclèctic s'imposava com un signe d'aquells temps. Cal, doncs, tenir una visió de conjunt d'altres obres i actors d'aquells anys, i no una de triada que en menyscabi la complexitat. La dificultat de definició de Dau al Set (només una revista?, un grup?) i la seva nòmina tancada tampoc no facilita la comprensió d'unes iniciatives en què van intervenir personatges i obres d'una diversitat considerable.

Jaume Pont ha assenyalat perspicaçment que, en abordar la reiterada clau eclèctica d'Entregas de Poesía o de la munió de revistes literàries d'aquells anys, cal detectar una dinàmica imposada pel règim del moment:

L'estratègia era molt simple. Es tractava de camuflar interessadament, mitjançant la cortina de fum de la lírica, les consignes bellicistes i patrioticopolítiques del nou règim, donant així una aparença de normalitat cultural. Més enllà de les línies poètiques de les revistes, aquestes acaben intercanviant noms de poetes i poesia de registres molt diversos. Aquesta operació es feia en nom de la Poesia, amb majúscules, en nom de la necessitat de publicació i, en últim terme, en nom d'un consens pragmàtic entre poetes que atenuava la belligerància de corrents i tendències (Pont 2007, 53).

En efecte, posar els ulls en blanc davant la poesia (o l'art) i percaçar l'inefable podien ser activitats que facilitaven les coses a un règim que s'imposava a ferro i foc, i que havia aconseguit encapsular precisament aquesta poesia en la més radical autonomia respecte a la societat.

Alfonso Pintó va ser moneda de canvi de moltes d'aquestes publicacions com a poeta i com a traductor, amb la qual cosa va assolir, pel que recullen les seves pàgines, una notable presència, de manera que es fa difícil d'arrenglerar-lo en una clara tendència estètica d'acord amb la seva participació en publicacions concretes. En efecte, aquesta circumstància s'escampa a la majoria de l'activitat poètica de llavors. Espadaña, per exemple, la revista que va mantenir el pols antiavantguardista i que feia valer la rehumanització de la poesia, va acceptar algun contínuum surrealista, com és el cas de Cirlot o del mateix Pintó. I, en aquest moviment de reciprocitat, els corrents estètics es desplegaven sense envigorir-se, així com també autors o tradicions anaven saltant d'una publicació a una altra, 
redoblant l'eco de la seva descoberta, sense assolir la subjecció de la seva lectura més pregona. Fa l'efecte que això passa amb la moderna poesia brasilera o també amb la catalana. Els noms hi són, és destacada la presència d'alguns poetes acompanyats per padrins amb solvència prescriptora, però del Brasil o de Catalunya no en queda un dibuix poètic precís.

Tal vegada les dues edicions barcelonines de Cobra Norato, de Raul Bopp, puguin mostrar la limitació d'aquest escenari. L'editor mateix, Alfonso Pintó, que es presenta com un traductor experimentat del portuguès, manifesta a la introducció que un llibre com Cobra Norato no es pot traduir. Una creació poètica tan arrelada al territori amazònic, una experiència tan personal fora del comú, és, segons l'editor, incopsable fora del domini lingüístic en què s'ha creat. ${ }^{33}$ Bopp és un nom cabdal de l'avantguarda històrica brasilera constituïda al voltant de la Semana da Arte Moderna a São Paulo l'any 1922. Va ser fundador del moviment antropofágico i del Pau-Brasil i, com un nodrit elenc de la intellectualitat brasilera del seu temps, va viure, per valisa diplomàtica, l'evolució de la modernitat a Europa i a tot el continent americà. L'edició de Cobra Norato a cura de Pintó inclou tres notes de Bopp extretes d'anteriors edicions que informen amb escreix de l'aspiració radicalment regressiva, atàvica, del moviment antropofágico per així esdevenir força renovadora i genuïnament avantguardista. ${ }^{34}$ El poeta brasiler estava atent, com no podria ser d'altra manera, al moviment surrealista que irrompia amb força arreu i, és clar, a la

33 «Traté, en más de una ocasión, de insuflar forma española a este atávico, simple y encendido mundo amazónico; pero no fue posible. Y algo no menos cierto existe en relación a esa versión española que a todos parece inexcusable. Me refiero que la dificultad no estriba en la ineptitud del traductor, sino en la misma entraña del poema, que, como la Reina Lucía de sus versos, parece preso para siempre en los larguísimos brazos de sus ríos. Esa avidez de Cobra Norato por su tierra se traduce, ni más ni menos, en su esoterismo de siete llaves. Por eso el más brasileño de los libros brasileños, como alguien le llamó, debe permanecer en la misma intacta virginidad en que fue nacido, cerrando con un veto el paso de sus caminos», citació d'Alfonso Pintó (Bopp 1954, 1).

34 «Vamos descer à nossa pre-história. Trazer alguma coisa dêsse fundo imenso, atávico. Catar os anais totêmicos. Remexer raízes da raça, com um pensamento de psicanálise. Dêsse reencontro com as nossas coisas, num clima criador, poderemos atingir a uma nova estructura de idéias. Solirários com as origens. Fazer um Brasil à nosa semelhança, de encadeamentos profundos [...] Os que iniciaram o movimento preocupam-se en chamar atenção para um Brasil diferente, num privilégio de descobrir coisas. Fixar meridianos para um novo "Diálogo das Grandesas”. Raça de homens que se orgulhavam de engulir o seu semelhante! (cualquer coisas de honroso para a nossa Pré-história)» (Bopp 1954, 15-16). 
seva adaptació als diversos territoris i circumstàncies. Publicada en primera instància el 1931, Cobra Norato, que en origen havia de ser una obra adreçada a un públic infantil, s'inspira en un viatge de l'autor per l'Amazònia. Bopp la va anar donant a conèixer en les seves successives edicions als indrets on era destinat com a diplomàtic. I és durant aquest periple professional quan va anar disseminant volums difícils de trobar. ${ }^{35} \mathrm{~A}$ la segona edició barcelonina de Cobra Norato del 1954 a cura d'Alfonso Pintó hi afegeix trenta-cinc poemes més, dels quals, vint-i-quatre no havien estat recollits en cap altra edició.

El primitiu ja va ser un element constitutiu de la recerca avantguardista i, en el cas surrealista, també va ser definidor. Aquest valor antiretòric suposarà, en la immediata postguerra europea, entre d'altres conseqüències, una aposta per les cultures perifèriques procedents del món colonitzat, per altres veus no malmeses per la decadent cultura occidental. L'impacte, per exemple, de Cahier d'un retour au pays natal d'Aimé Césaire -l'edició del 1947 va anar acompanyada del pròleg i de la benedicció d'André Breton - atorga una vibrant modernitat a les veus no europees. De l'Amazones, màxim exponent de l'antropofàgia, emergia aquesta força renovadora i alhora genuïnament brasilera. Com ha assenyalat Raúl Antelo, l'avantguarda brasilera (i llatinoamericana per extensió) s'ha nodrit sovint d'aquesta paradoxa: la identitat antropofàgica seria la constant construcció d'una diferència i, alhora, la recerca d'una manera brasilera de ser universal (Antelo 2008).

Certament, el primitiu no era una descoberta d'aquells anys de postguerra. A la revista Dau al Set, per exemple, s'estava al corrent del component màgic o magicorealista que havia discorregut abans de la Guerra

35 Bopp va ser cònsol a Los Angeles (1941-1944), primer secretari de l'ambaixada a Lisboa el 1945, cònsol a Zuric entre 1946 i 1948 i cònsol general a Barcelona el 1951. Això vol dir, doncs, que no coincideix amb Cabral de Melo. Tornà a Suïssa com a ministre de primera classe a Berna entre 1954 i 1958 , i va ser nomenat ambaixador a Viena entre el 1958 i el 1962. Va tenir contactes amb Max Bill, Marc Chagall i Joan Miró (Peixoto 2010, 98-118). Una dada significativa és que Bopp va ser destinat a Berna, segons consta en la pàgina de l'ambaixada brasilera a Suïssa, entre el 22 de juny de 1954 i el 17 de desembre de 1958. Un període, doncs, en què havia de coincidir amb Alfonso Pintó, el qual va signar cròniques artístiques des de la ciutat suïssa per a la revista Goya des de l'any 1956 fins al 1967. Maite Torroella va explicar a Alessandra de Carvalho que Alfonso Pintó es va incorporar com a funcionari, tot i ser ciutadà espanyol, al consolat general del Brasil i, després, va passar a Berna (Carvalho 2014, 476). 
Civil. S'ha escrit de la importància que el grup expressionista alemany i Franz Roh van adquirir a Espanya - i concretament a Catalunya- per la introducció del concepte "realisme màgic". L'obra de Roh va ser traduïda el 1927 per Revista d'Occidente i el realisme màgic va ser present en les polèmiques avantguardistes. ${ }^{36}$ Aquesta edició madrilenya duu de frontispici una reproducció de Rousseau, el pintor duaner que, en la postguerra barcelonina, va propiciar l'encontre casual (o màgic) entre Joan Brossa i Joan Ponç.

El magicisme de Dau al Set és en bona mesura continuador d'aquest debat i va ser presentat com un renovament del surrealisme. ${ }^{37}$ La desorientació de les avantguardes després de la Segona Guerra Mundial, l'exigit retorn als (suposats) orígens o el descart de la norma propicien la confiança en unes arts vinculades a allò atàvic i capaces de restablir certa coherència a la realitat. L'aposta pel primitiu s'ha d'entendre com una impugnació dels valors que fonamenten la cultura occidental i el seu ert racionalisme. Cobra Norato esdevé un mirall ben nítid d'aquesta recerca d'un altre, misteriós - intraduïble-i màgic.

Parallelament a l'aproximació del Brasil a la cultura barcelonina de final de la dècada dels cinquanta, a Itàlia es consolidava un altre focus important de recepció, que tindria impacte a la península Ibèrica. L'acció del poeta Murilo Mendes a Roma, llavors professor a La Sapienza, es va fer notar en Giuseppe Ungaretti, el qual es va convertir en el seu traductor a

36 Roh buscava un art que fos experiència, entre d'altres coses, de l'encontre del desconegu en el conegut, a partir de pràctiques formals i tècniques d'estranyament: «Con la palabra "mágico", en oposición a "místico", quiero indicar que el misterio no desciende al mundo representado, sino que se esconde y palpita tras él» (Roh 1927, 11). A Catalunya, per exemple, un dels més originals teòrics del moment, Magí E. Cassanyes (1928), se’n feia ressò. Cassanyes va continuar després de la guerra tutelant el magicisme (Cirici 1970, 236-237).

37 Cirlot en el primicer Diccionario de los ismos (1949) retorna al concepte de realisme màgic i el vincula a Tàpies, Cuixart i Ponç: «Como consecuencia del interés despertado por la magia, en sus relaciones con el surrealismo, y de la impotencia que parece tener actualmente este último movimento para seguir engendrando nuevas y típicas creaciones, procediendo de las aludidas concomitancias y también del interés desvelado por el sector más oscuro del realismo mágico, se está produciendo un brote profundo y grave de filiación estrictamente mágica, con expresiones en la lírica y en la plástica. Podria ser acaso este movimiento, después de la oscilación hacia el abstractismo que se viene constatanto desde 1940 aproximadamente, el horizonte de una próxima renovación espiritual y artística» (Guigon 1992, 23; i també Guigon 1999, 145-149). 
l'italià i un mitjancer reconegut d'altres escriptors brasilers a Itàlia. ${ }^{38} \mathrm{Cal}$ tenir present que Ungaretti, al seu torn, havia estat professor abans de la Segona Guerra Mundial de literatura italiana a São Paulo. El Brasil, l'indret indòmit i verge, és també l'espai colonitzat per una cultura ibèrica marcada pel barroc — que al Brasil va tenir formes pròpies i popularitzades. Ungaretti, intèrpret de Góngora i actualitzador indiscutible del barroc o neobarroc al segle xx, fixa la mirada cap a aquesta tradició americana que sembla ajustar-se a les seves afinitats. A l'altre costat de l'Atlàntic, amb la lliçó barroca hi havia confluït l'avantguarda i el surrealisme.

Murilo Mendes va maldar aquells anys per convertir Espanya en un lloc preeminent de la seva poesia fins a ser l'eix d'un dels seus poemaris més reconeguts: Tempo espanhol (1959). De fet, aquest llibre ens duu no només a paisatges i filiacions estètiques, sinó també a personatges concrets d'aquells anys de proximitat amb Espanya. Concretament, un dels poemes que sembla copsar una experiència personal, «Crianças de Tarragona", va dedicat a Alfonso Pintó i fa pensar en el seu possible encontre a la ciutat catalana. Es fa palesa la tendència d'una recuperació d'un art ancestral i que es vol autèntic, un element que definia les avantguardes espanyoles en aquell moment. Trobem, per exemple, «Cabeça de touro maiorquina» 0 «As carpideiras», un poema inspirat en el fresc romànic $a$ l'actual Museu Nacional d'Art de Catalunya i que representa unes ploraneres - la mateixa pintura que pocs anys abans havia cridat l'atenció a Jean Cocteau. Són poemes que tant connecten amb els pressupòsits de l'Escola d'Altamira com amb la reivindicació de l'art medieval feta per Dau al Set o de manera més evident - o oportunista- pel grup Taüll. Hi ha també en Tempo espanhol poemes dedicats a Rafael Santos Torroella i la seva esposa, Maite Bermejo, o a Enric Tormo i la seva esposa, Maria Ballester; és a dir, a un cercle que inequívocament ens duu a Cobalto i a Dau al Set, els focus barcelonins receptius de cultura brasilera.

Murilo Mendes, per la seva part, confirma allò que també és tan evident en Cabral de Melo: l'entusiasme per Joan Miró, que és objecte d'un poema.

38 L'obra de Giuseppe Ungaretti, Vita d'un uomo (1974), aplega diversos assajos de crítica literària, tres dels quals dedicats a escriptors brasilers: Murilo Mendes, Vinícius de Moraes i Oswaldo de Andrade. N’he consultat la traducció i edició veneçolana a Ungaretti (1977). 
A la Fundació Joan Miró de Barcelona es conserva un exemplar dedicat de Tempo espanhol o altres testimonis de reconeixement. ${ }^{39}$

Tempo espanhol és segurament el poemari que fa més evident la presència d'un tema, l'hispànic, en la poesia brasilera del segle xx. Una tematologia que recull clixés, paisatges, experiències o personalitats. Cabral de Melo també en va ser un conreador: la tauromàquia i el flamenc en la seva poesia ho testimonien, així com l'evocació de personatges com Joan Miró o Joan Brossa. No crec que sigui pertinent destriar l'espanyol del català estricte en aquests casos. Ara bé, tant Murilo Mendes com, és clar, Cabral de Melo van ser molt conscients de la diversitat cultural hispànica i ibèrica, fins al punt que del català i de Catalunya se n'arriben a configurar una imatge singular amb algun o altre ressò en la poesia brasilera contemporània. He esmentat abans Fernando Gutiérrez i La poesia catalana. Els contemporanis (Barcelona: José Janés, 1947). Aquest volum va arribar al Brasil — aviat, el 1951 — a mans d'un dels grans poetes de la segona meitat del segle xx, Augusto de Campos. L'escriptor brasiler va quedar encisat pel català, per la seva sonoritat que li reportava l'antiga llengua dels trobadors. I es va fixar en un poeta i en un poema que havia traduït Cabral de Melo el 1949: Josep Palau i Fabre i el seu «Sonet intrauterí», als quals va dedicar, molt més tard, el text «Paraulas para Palau» (Campos 2009). Qui vulgui veure com aquesta llavor va fructificar en la poesia visual concreta, que vegi l'extraordinari poema del germà d'Augusto, Haroldo de Campos, «Nascemorre» del 1958.

39 A la dedicatòria Murilo escriu: «A Joan Miró, grande pintor, grande poeta, homenagem de viva admiração e afecto de Murilo Mendes. Roma, Janeiro 1960.» La Fundació Miró disposa d'una carta, datada el 26 de desembre de 1968, en què Murilo Mendes li ofereix un altre poema, escrit en francès, que després serà recollit a Retratos-Relâmpagos en portuguès. 
E que o "homem", a fome, o frio, o trabalho, etc., etc., são o que há de mais revolucionário.

Carta de João Cabral de Melo a Joan Brossa (veg. Apèndix, infra, c.1)

El que té d'excepcional la relació entre Cabral de Melo i la cultura catalana és l'ambició. No sé si trobaríem un cas similar d'un autor estranger que, en una estada curta i motivada per qüestions estrictament professionals, tingui un propòsit tan interventor. I certament no tot pro domo sua. Malgrat fer gala d'una ideologia a voltes doctrinària, és notori que aplicarà l'eclecticisme com el que corresponia a la pròpia situació personal i professional. Cabral de Melo es va haver d'ajustar a contextos que exigien flexibilitat. Aquí rau una de les principals paradoxes: mentre la seva poesia i la seva poètica reclamaven rigor i una bona dosi d'ascetisme, la seva professió li exigia contínuament contemporitzar. Diplomàtic de carrera que representava llavors un país autocràtic, en un interregne just abans de l'última presa de poder de Getúlio Vargas, esdevindrà un model d'escriptor de clara adscripció marxista, fet que va motivar un greu entrebanc professional quan, en la seva missió posterior a la barcelonina, a l'ambaixada de Londres li és obert un expedient disciplinari.

Com sovint ell mateix va voler fer constar, Cabral de Melo no es considerava tout court un poeta brasiler. No només perquè les circumstàncies professionals el van mantenir fora del seu país, sinó sobretot pel desig de crear-se una tradició des d'una genealogia no nacional. Se sentia més proper a Stéphane Mallarmé, Paul Valéry, Williams Carlos Williams, Francis Ponge o Jorge Guillén que a cap altre poeta connacional suspecte d'un lirisme i, per tant, d'un subjectivisme, dels quals sempre va maldar per desempallegar-se. "Jamais se rendeu — ha escrit Haroldo de Campos-ao "vício retórico nacional" e ao sentimentalismo epidérmico, encontradiço em tantos poetas que fazem praça de modernidade e até de vanguarda», perquè sempre va procurar «o lugar cartesiano da lucidez mais extrema» (Campos 2000, 27) en autors de diverses tradicions, però coherents en la seva afinitat selectiva. 
Raó de més per considerar notori el fet que Cabral, en el primer moment de la seva estada a Barcelona, es volgués aproximar a Carles Riba, el Riba tal vegada més depurat i abstracte, el que procurava el poètic en la nuesa, en definitiva, el que havia après la lliçó de l'autor de Cántico. Cabral de Melo va defensar una vegada i una altra que amb emoció no s'escriu una obra d'art, si bé l'obra d'art és un objecte que pot provocar una emoció. La «poesia de confessionari» s'havia de desterrar, també l'espontaneïtat, el lirisme o la facilitat. El treball intellectual, tenaç i eminentment visual havia de superar la temptació auditiva romàntica. A la «Introdução» de les versions de poetes catalans, Cabral de Melo descrivia la poesia catalana actual, la del 1949, com una poesia que estava al cas de les recents teories del llenguatge, un fet que - segons el brasiler- li atorgava un caràcter específic: «uma poesia mais de professores e filólogos do que de jornalistas, de conscientes mais do que inspirados» (Neto 1949, 29). En ponderava especialment la seva «auto-disciplina e lucidez», valors que Cabral de Melo també s'exigia. Una manera d'apropar-se a Riba podia ser regalar-li Psicologia da Composição, el poemari que acabava d'imprimir ell mateix i que anava encapçalat per una citació de Jorge Guillén, «riguroso horizonte». Havien de compartir moltes coses i sobretot l'admiració per Valéry, aquell que no creia, o amb prou feines, en la inspiració i que, per contra, apostava per la composició, per aquest sobri terme professional. D'aquest reconeixement en restaran unes poques tankes de Riba traduïdes per Cabral de Melo per a la revista Ariel amb una presentació de Joan Triadú.$^{\circ 0}$ Però, com més endavant veurem, aquesta primera simpatia del brasiler pel poeta català esdevindrà desgrat. I, aquest primer apropament, un camí tancat.

Tanmateix, se n'obrirà un altre i de molt fecund, el de Joan Brossa, que signarà la traducció de tres poemes («A bailarina», «As nuvens» $\mathrm{i}$ «A paisagem zero»), extrets del poemari O Engenheiro (1942-1945) per a la revista Dau al Set en el número de juliol-agost-setembre del 1949. En aquest

40 Aquestes traduccions de Cabral de Melo aparegudes a Ariel seran després incloses en el volum Versions de poesia catalana (Barcelona: Joan Sallent, impressor, 1962), en què també es va incloure la versió d'«A Maiorca, durante a Guerra Civil» de Bartomeu Rosselló-Pòrcel, publicada primerament a Neto (1949, 144-145). 
mateix número, Santos Torroella, que havia presentat Brossa a Cabral de Melo, hi va publicar el poema «Nadie», dedicat al poeta brasiler.

El rastre més decisiu de Cabral en Brossa es troba a Em va fer Joan Bros$s a$, publicat el 1951, amb un pròleg del brasiler, un dels textos més importants per entendre l'evolució poètica al nostre país. Em va fer Joan Brossa, segons Tàpies, és fruit de la influència de Cabral sobre Brossa, fins a tal punt que el poeta català el trobava estrany en el conjunt de la seva obra i va dubtar d'incloure'l al recopilatori Poesia rasa (Tàpies 2003, 238). Fer confluir avantguarda i realisme era l'objectiu marcat. Un objectiu que passava per la ruptura d'unes determinades tendències de continuïtat entre l'avantguarda anterior a la guerra i el seu lligam amb els anys cinquanta. L'automatisme o el magicisme començaven a ser suspectes per uns creadors que volien substantivar un compromís amb la realitat, sense caure en l'aridesa del realisme socialista i el seu apegalós sentimentalisme. En efecte, els realismes i les avantguardes marcaran, i de quina manera, l'evolució de l'art i de la literatura en les següents dècades. Josep M. Balaguer va assenyalar dues direccions de debat entre els membres de Dau al Set. Per una banda, destacava la figura de Cabral de Melo, que va incidir en una tradició que es pretenia vincular amb el nexe entre el marxisme i el surrealisme dels anys vint i trenta; per altra banda, la que defensava Arnau Puig de total adhesió al model sartrià (Balaguer 2000, 51). Puig va retratar políticament Cabral com un doctrinari, afí a plantejaments estalinistes (Puig 2004, 11). Tàpies, que també en va destacar el caràcter adoctrinador, per contra, el va veure com un reactiu que els va fer descobrir un nou art allunyat dels plantejaments del realisme socialista, una figura heterodoxa en el marc de la rigidesa del comunisme oficial d'aquells anys.$^{41}$ Són visions contraposades, però a la vista de les cartes que annexo a aquest treball sembla clara la seva vinculació a un realisme i humanis-

41 Antoni Tàpies, en el seu relat biogràfic i seguidament en l'evocació de Cabral de Melo, fa una definició del nou humanisme molt en la línia del brasiler: «El humanitarisme d'avui ja no tenia res a veure amb un mer "sentimentalisme" i una estovada "caritat", fomentats en gran part per l'Església [...] Calia, doncs, estudiar les coses a fons i calia conèixer les organitzacions i les personalitats que ja estaven preparades per a aquesta lluita revolucionària [...] Gràcies a Cabral, doncs, vaig entrar llavors — evidentment amb més sentiment entusiasta que amb real coneixement - en el polèmic món de l'“art compromès”» (Tàpies 2010, 209-210 i 233-235). 
me d'abans de la guerra, al lligam que s'havia produït entre el marxisme i el surrealisme en figures com les d'Henri Lefebvre i Georges Politzer. Balaguer, a més, fa una consideració que convé ara destacar:

Em va fer Joan Brossa podia ser vist com una resposta, no vull dir necessàriament que de manera conscient i directa, al model de compromís sartrià $\mathrm{i}$ alhora com una fase de la progressiva presa d'una posició compromesa, que acabarà tenint una clara dimensió política de la seva obra i el conjunt de les seves activitats, una fase que, d'altra banda, prefigura allò que Barthes, debatent amb Sartre, reclamava a l'escriptor engatjat, que la seva obra fos una reflexió sobre les condicions que fan possible una literatura compromesa. (Balaguer 2000, 59-60)

En efecte, l'autoreflexió, no només del poeta i la seva funció social, sinó — sobretot - de l'objecte poètic, acabarà sent la gran aportació tant de Cabral com de Brossa.

Alexandre Pinheiro Torres, en la introducció als Poemas escolhidos (1963) de Cabral de Melo, va posar en relació el poeta brasiler amb Alain Robbe-Grillet per la seva croada desmitificadora contra la metafísica, contra el simple misteri, contra qualsevol succedani de romanticisme i, fins i tot, contra la tan recurrent angoixa sartriana d'aquells anys cinquanta. Cal buscar explicacions objectives, científiques, tècniques a allò que produeix estranyesa. Ho feia explícit en un dels poemes escrits just abans d'arribar a Barcelona, «O Engenheiro» - en què l'enginyer val pel poeta:

O engenheiro sonha coisas claras: superfícies, tênis, um copo de água.

O lápis, o esquadro, o papel;

o desenho, o projeto, o número:

o engenheiro pensa o mundo justo, mundo que nenhum véu encobre.

Justícia i transparència són indestriables en aquest paisatge que l'enginyer projecta: una poesia banal en la seva acerada objectivització, en la seva irremeiable fredor, en l'acceptació estoica de les coses. És una escriptu- 
ra compromesa sense fer cap concessió a un prosaisme sentimental tan característic també d'aquells anys ni tampoc a un surrealisme sempre sospitós d'una espiritualització implícita. La desartització de la literatura, la poesia despoetitzada, passa per no trobar una escissió entre l'home i el món: només hi ha distància entre l'home i els objectes. Tot rau en un problema del llenguatge. L'escriptor conscient sent la diferència entre la riquesa de l'objecte real i la falsedat que l'artista de la paraula proposa. Interessa allò que és en l'exterior, el poema objectivat, i que entén la natura com a pur objecte (i en la seva pura bellesa). S'atorga prioritat a la descripció de les qualitats més primàries (figura, moviment, extensió i forma) més que no pas a les secundàries (color, olor, gust).

Psicologia da Composição (1946-1947) s'inicia amb uns versos que auguren un dels pilars de la poètica brossiana: «Saio de meu poema / como quem lava as mãos». Una poètica que ubica l'home històric immers en el quotidià, si no en el banal, per fer-nos veure que tenim davant paraules, elements que xifren en abstracció individus o realitats concretes. El llenguatge, doncs, forma part de la realitat i ho fa en dos sentits: es concreta en objecte lingüístic i predetermina la nostra percepció de la realitat. Brossa, com Cabral de Melo, procura crear un objecte lingüístic que pugui ser contemplat alhora dins del poema. ${ }^{42}$ Un joc irònic de desdoblament, d'escenari d'on es pot entrar i sortir que, com els versos suara citats de Cabral, presagia els entra-i-surts brossians característics. Com s'ha dit sovint, l'espai creat per Brossa en els seus poemes té molt de teatral (i de pictòric) per la seva irrefrenable pulsió de fragmentar la realitat, de juxtaposar escenes o converses, o simplement enumerar i desplegar, doncs, aquest espai per ser contemplat per mitjà d'un llenguatge que és constantment impugnat.

El record de Cabral de Melo no va trigar gaire a esborrar-se o, com a mínim, a fer-se imprecís i, doncs, contradictori. Les evocacions personals han tendit a destacar-ne l'apologètica marxista i no tant la significada aportació estètica. Voldria pensar que un ressò dels seu pensament hi és, per exemple, en la presentació que Santos Torroella va fer per a l'exposició

42 «Durante seu trabalho, o poeta vira seu objecto nos dedos, iluminando-o por todos os lados. E é ainda seu trabalho que lhe vai permitir desligar-se do objecto criado. Este será um organismo acabado, capaz de vida própria. É um filho, com vida independente, e não um membro que se amputa, incompleto e incapaz de viver por si mesmo» (Neto 2003 $b, 22)$. 
«El Objecto» per a o Figura a la Galeria Gaspar (Barcelona, 1961). Cabral reivindicava una vegada i una altra «fazer poesias com coisas», guanyar precisió en el llenguatge, esbandir un buit fantasmal. En l'escrit «Poesia e composição» defensava: «a poesia é talhada, contrafeita à ideia de inspiração, muitas vezes, o desgosto [impõe-se] contra o vago e o irreal, contra o irracional e o inefável, contra qualquer passividade e qualquer misticismo, e muito de desgosto, também contra o desgosto pelo homem e sua razão» (Neto 2003 $b$, 733). També a l'assaig sobre Miró, en la «psicologia de la seva composició», Cabral hi deia: «en Miró, més que en cap altre artista, veig una enorme valorització del fer. Es pot dir que mentre que en altres el fer és un mitjà per arribar a un quadre, per realitzar l'expressió de les coses anteriors i estranyes a aquell acte mateix de realitzar, el quadre, per a Miró, és un pretext per al fer. Miró no pinta quadres. Miró pinta» (Neto 2008, 54).

Com esmentava a l'inici, pocs rastres trobem sobre l'estada de Cabral de Melo, nomenat cònsol general del Brasil a Barcelona, a final dels seixanta. Amb tot, una significada influència de Cabral de Melo es va fer notar també en un poeta català posterior a Brossa: Pere Gimferrer. Gimferrer justificava les constants imaginístiques de la seva primera poesia, en una entrevista de final dels setanta, per la influència del poeta brasiler:

surgen de un consejo fundamental para mi que me dio el poeta brasileño João Cabral de Melo. Me recomendó que me fijara en las formas primitivas, me citó a Villon y a Berceo pero igual hubiera podido citarme la Chanson de Roland o Ramon Llull. Me recomendó que, como los primitivos, utilizara cosas que pudieran visualizarse, no cosas abstractas ni imágenes no visualizables por el lector. Y esto, con muy pocas excepciones, lo he practicado rigurosamente. Por tanto, si es algo que el lector puede imaginar visualmente, es algo que funciona. (Munné 1976, 43) ${ }^{43}$

Com el mateix Gimferrer va dir de Brossa, manllevant-ho de J.V. Foix, calia crear «el real poètic», també obstinadament allunyat del «misteriós

43 A aquestes declaracions es refereixen, de manera polèmica, Víctor García de la Concha, Martínez Sarrión i Guillermo Carnero per rebaixar el pes poètic i crític de Cabral de Melo (García 1986, 19 i 23). 
mal lubrificat i el tèrbol» i, per tant, procliu a la simplicitat, la claredat, l'objectivitat, la plasticitat i, sense ombra de paradoxa, al realisme. I, per aquest camí d'investigació, es va trobar Cabral de Melo.

\section{Apèndix}

A continuació edito seguint criteris diplomaticointerpretatius dues cartes de Cabral de Melo a Joan Brossa (c.1 i c.2), ${ }^{44}$ un colofó que pretén sintetitzar alguns dels elements desenvolupats anteriorment. L'estil directe, tal com raja, de Cabral, fa tothora evident la seva voluntat prescriptora. En destaco, sintèticament, la seva croada antisurrealista, antimistèrica - contra tot allò que havia practicat Dau al Set - o anticasticista, que el situa frontalment davant del brasilerisme comú en bona part dels seus compatriotes. També hi sobresurt la belligerància contra el mer formalisme, contra una literatura burgesa que s'ha situat en la més radical autonomia respecte de la societat. I per aquest front acaba rebent Carles Riba i tot el que representava el neonoucentisme o el postsimbolisme del moment. Comptat i debatut, és allò que la polèmica antologia de Castellet i Molas del 1963 va intentar també desemmascarar: la Catalunya ideal. Cabral no s'està d'assenyalar una nova orientació per a la cultura catalana que passava per l'abandó de magicismes o surrealismes, esdevinguts mers formalismes que havien perdut la pulsió autèntica d'avantguarda, $\mathrm{i}$ l'avançament cap a un nou humanisme, un nou realisme que també eren - havien de ser - avantguarda. En definitiva, un rumb que, pel que fa a Joan Brossa, va quedar prou palès en la seva trajectòria. 


\section{C.1}

\section{Carta enviada des del Consulado Geral dos Estados Unidos do Brasil em Londres, [mata-segells:] 8/1/5145}

8.1 .951

Meu caro Brossa,

Muito obrigado pela sua carta. Tenho andado realmente ocupado neste Consulado em Londres. Aqui se trabalha realmente. E como os primeiros meses num país são os mais difíceis, eis que me sinto sem cabeça para escrever aos amigos.

Mas não estou olvidado, pode estar certo. Ainda há poucos dias, quando estive em Paris, falei de você com o Cuixart e com Tàpies. Compramos juntos alguns livros e combinamos que, depois de lidos, eles os enviariam a você, a fim que os faça circular por aí. ${ }^{46}$

Gostei muito do espírito de Tàpies e Cuixart em Paris. Eles haviam já sentido o choque da decepção, no primeiro contacto com a arte formalista em seu próprio ninho. Eu, há tempos, havia previsto a coisa. E vê-la confirmada neles me alegrou. Porque isso mostra que todos os que são autenticamente artistas, e homens, têm que compreender o que há de moribundo e de novo no mundo atual. Ora, depois de saber o que está moribundo e o que está nascendo, só os suicidas ou os deformados podem preferir o moribundo.

45 Carta des de Londres a Joan Brossa, 8 de gener de 1951. Productor: Joan Brossa. Emissor: João Cabral de Melo Neto. Fons Joan Brossa. Número de registre: A. JBR. 00372. Topogràfic: BROSSA_CORRES_PER_JB_CABRAL_oooo1. Full manuscrit amb ploma, amb capçalera impresa del consolat brasiler a Londres.

46 Sobre l'estada a París i l'encontre amb Cabral de Melo hi va fer referència Antoni Tàpies. Segons el pintor, va ser durant aquesta estada quan va començar a donar un contingut social a la seva obra. Cabral el va acompanyar a diverses llibreries d'orientació marxista. Va llegir, entenem que per la intervenció del brasiler, escriptors revolucionaris russos com Gueorgui Plekhànov o Nikolai Txernixevski. I també Henri Lefebvre i Georges Politzer (Tàpies 1974, 183 i sobretot Tàpies 2010, 242-243, que a la nota 2 fa una valoració en perspectiva de les lectures recomanades per Cabral). També val a dir que Tàpies va conèixer a París, sembla que per mediació de Cabral, el pintor brasiler Cícero Dias (Tàpies 2010, 237). 
Gostei de saber que v. está trabalhando. Isso é importante. Cada dia mais me convenço que do grupo de vocês se pode esperar grandes coisas. "Pero" 47 não no caminho do Dau al Set, precisamente.

Tenho muita curiosidade na antologia do Salvat-Papasseit. E muita no livro que o Santos vai editar. Tenho, inclusive, bastantes esperanças na colaboração de vocês e do Santos. O Santos conserva em si o melhor do espírito realista e humanista da Espanha de antes da guerra. E esse espírito não desapareceu: talvez tenha adormecido um pouco. ${ }^{48}$

Da colaboração de todos vocês pode surgir um grupo fecundíssimo: um grupo realista e humanista (não no sentido de humanismo universitário; sim, de fé no homem). E esse grupo pode ser decisivo na hora atual. Por um lado ele se afirmará contra todos os existencialismos, surrealismos, magicismos, negadores da realidade e do homem. E por outro se afirmará contra todos os fabricantes de sonetinhos, odesinhas gregas com floretas, casetas e hortetas (Riba, etc.). ${ }^{49}$

Fique seguro: o mundo - e a cultura - chegaram a um tal ponto que a palavra "paz" é uma palavra suspeita. E que o "homem", a fome, o frio, o trabalho, etc., etc., são o que há de mais revolucionário.

Perdoe que lhe escreva em português. E também o tom pesado desta carta. Roubei para ela um "rato" $5^{\circ}$ do serviço consular e aqui não posso fazer melhor.

Grande abraço aos amigos: Ponç, Tormo, Puig, Castell[s], Santos, Tharrats a quem vou escrever.

\section{Grande abraço do seu}

\section{J. Cabral}

47 "Pero": manlleu del català (o castellà), en portuguès "mas".

48 No sé a quina antologia de Salvat-Papasseit es pot referir. Santos Torrorella, en efecte, va ser l'editor d'Em va fer Joan Brossa. La carta confirma que Santos era el nexe entre els creadors de Dau al Set i Cabral. El poeta brasiler en subratlla la personalitat «realista e humanista», la representativa dels valors republicans pels quals va combatre durant la Guerra Civil, ometent les seves responsabilitats en la cultura oficial d'aquells anys.

49 Evidentment, està estrafent el català: «floretes, casetes i hortets». Aquest fet palesa, una vegada més, la seva voluntat interventora en el marc precís català.

50 Manlleu del castellà que procura un efecte còmic: "rato", en portuguès, és "rata". 


\section{C.2}

[Mata-segells:] London 16 abr 1951

Brazilian Consulate General, 32, Green Street, Mayfair, London, W. 1 Telephone Grosvenor $7441 / 4^{51}$

Meu caro Brossa,

Acabo de receber seu postal. Eu já havia falado, em carta ao Santos, do "vosso" livro. Preferi falar ao editor, porque a contribuição do editor é o que há de novo e não comentado. Porque do texto, se o prefaciei, já disse todo o bem que me parecia e que me continua a parecer.

V. me fala que tem continuado a escrever. Não se pode ter uma cópia dessas últimas coisas? Você começou um caminho e já não o pode abandonar. Há dias atrás lhe mandei um livro do Nazim Hikmet, que a estas horas v. já terá recebido. ${ }^{52}$ Vou mandar outras coisas. Nós, artistas formalistas, temos que renovar completamente nossa sensibilidade. Este é mesmo o primeiro passo que temos de fazer para poder criar outra coisa, nova e não cadáver. Depois da certeza racional de que é preciso mudar, de que essa arte que fazíamos é a arte de uma classe moribunda, de que há uma classe nova, que está subindo na história, é preciso identificar-se com essa classe, com suas lutas, com suas preocupações, etc. Ora, a função nossa, de intelectuais, é ajudar, com nossos meios nessa luta. E a função especial de nós, poetas, é cantar essa luta, celebrá-la, e dar a essa classe a poesia que eles não têm hoje porque a cultura é privilégio da classe que domina

51 Carta des de Londres a Joan Brossa, 16 d'abril de 1951. Productor: Joan Brossa. Emissor: João Cabral de Melo Neto. Fons Joan Brossa. Número de registre: A. JBR. 00373. Topogràfic: BROSSA_CORRES_PER_JB_CABRAL_00oo2. Full manuscrit amb ploma, amb capçalera impresa del consolat brasiler a Londres.

$52 \mathrm{Hi} \mathrm{havia} \mathrm{precisament} \mathrm{l'any} 1951$ una forta campanya internacional de l'esquerra per demanar l'amnistia per al poeta turc Nazim Hikmet. 
atualmente. ¿Mas como poderemos ser entendidos deles, se temos sensibilidade diferente, se nos interessamos por fantasmas e mitos mentais, ao passo que eles se interessam é pela luta pela comida, pela casa, pela roupa? Você tem a grande sorte de trabalhar no meio dessa classe e para você o trabalho de pensar essa nova sensibilidade é mais fácil. Mas assim mesmo, para ajudá-lo, mandarei os livros e as coisas que possa.

Ando trabalhando muito e lendo bastante. Tenho lido tudo que tenho podido, do "outro" lado. E o efeito é que vou despertando para uma série de valores novos. Paralelamente, todos os formalismos, sobrerrealismos e outros, vão ficando distantes.

Em grande abraço aos amigos.

Um abraço do seu

João Cabral de Melo

\section{Bibliografia}

Amat, Jordi. 2005. «La Calandria (1951) en su contexto. La búsqueda agónica de un poetizar auténtico», 291-312. Dins Manuel J. Ramos Ortega, ed. i coord., Revistas literarias españolas del siglo XX (1919-1975). Madrid: Ollero y Ramos.

Antelo, Raúl. 2008. «El viaje horizontal», 261-273. Dins Sonia Mattalia, Pilar Celma i Pilar Alonso, ed., El viaje en la Literatura Hispanoamericana: el espíritu colombino. Madrid / Frankfurt am Maim: Iberoamericana / Vervuert.

Balaguer, Josep M. 200o. «"Em va fer Joan Brossa”, quin compromís!», 47-6o. Dins Ferran Carbó, Dolores Jiménez, Elena Real i Ramon X. Rosselló, Les literatures catalana i francesa: postguerra $i$ engagement. Barcelona: Publicacions de l'Abadia de Montserrat.

Bopp, Raul. 1954. Cobra Norato. Barcelona: Dau al Set.

Borràs Prim, Ramon. 1929. «Hèctor Villa-Lobos». Helix 3: 2-3.

Cabañas Bravo, José Miguel. 1991. «La primera Bienal Hispanoamericana de Arte. Arte, política y polémica en un certamen internacional de los años cincuenta». Tesi doctoral, Universidad Complutense de Madrid.

Campos, Agusto de. 2009. «Paraulas para Palau». http://www.cronopios.com.br/content. php?artigo $=10151 \&$ portal $=$ universidade.

Campos, Haroldo de. 200o. «Os “Poetas Concretos” e João Cabral de Melo Neto. Um testemunho». Colóquio / Letras 157-158: 27. 
Cano, José Luis. 1949. «Antología de poetas brasileños de ahora», Ínsula 46: 5.

—. 1962. «La poesía brasileña en España». Revista de Cultura Brasileña 2: 116-121.

Cántico, 1948-1949. «Notas». Cántico 8 (des.-gen.): 126.

Carvalho, Alessandra Vargas de. 2014. «Presença do poeta João Cabral de Melo Neto na Espanha: Relações literárias e em outros âmbitos da cultura». Tesi doctoral, Universitat de Barcelona.

Carvalho, Ricardo Souza de. 2007. «O Cavalo de Todas as Cores. Uma revista editada por João Cabral de Melo». Revista USP 73 (març-maig): 112-116. doi: https://doi. org/10.116o6/issn.2316-9036.voi73p113-116.

— . 2009. «Do catalão ao português: João Cabral tradutor». Revista de Letras 49: 137-149.

Cassanyes, Magí E. 1928. «Assaig de classificació del moviment de l'art modern». L'Amic de les Arts 26: 211-213.

Cerdà, Jordi. 2013. «Joan Ponç en los tristes trópicos». Revista de Cultura Brasileña. Nueva Serie 8: 172-205.

Cirici, Alexandre. 1970. L'art català contemporani. Barcelona: Edicions 62.

— . 2014. Diari d'un funàmbul. Les llibretes d'Alexandre Cirici Pellicer. Barcelona: Comanegra.

Delgado Gómez-Escalonilla, Lorenzo. 1988. Diplomacia franquista y política cultural hacia iberoamérica, 1939-1953. Madrid: CSIC.

—.1992. Imperio de papel. Acción cultural y política exterior durante el primer franquismo. Madrid: CSIC.

—. 2003. «Libros y revistas para América”: política cultural y producción editorial del Instituto de Cultura Hispánica», 23-39. Dins AA.DD., La huella editorial del Instituto de Cultura Hispánica. Ediciones Cultura Hispánica y otras publicaciones: estudios y catálogo (1944-1980). Madrid: Ministerio de Asuntos Exteriores / Fundación Mapfre Tavera.

Duran, Manuel. 1950. El superrealismo en la poesía española contemporánea. Mèxic: Universidad Nacional Autónoma de México.

Farrés, Ramon. 2017. «"Quinze poetas catalães”: l'antologia de João Cabral de Melo Neto que va donar a conèixer la literatura catalana al Brasil», 269-279. Dins Corinna Albert, Roger Friedlein i Imma Martí, ed., Els catalans i Llatinoamèrica (s. XIX ${ }_{X X}$ X). Viatges, exilis i teories. Barcelona: Publicacions de l'Abadia de Montserrat.

Foix, Josep Vicenç. 1935. «Poesia i revolució». Quaderns de Poesia 1: 1-4.

García de la Concha, Víctor. 1986. «Nueva poesía castellana. Ponencia I y Coloquio I». Los Cuadernos del Norte 3: 10-23.

Guigon, Emmanuel. 1992. «La escalera de la evasión. Constelaciones», 11-34. Dins Ciudad de Ceniza. El surrealismo en la posguerra espanyola. Catàleg. Terol: Museo de Teruel.

—. 2007. «Magicismo plástico», 145-149. Dins Dau al Set. Catàleg. Barcelona: MACBA.

Instituto de Estudios Hispánicos, 1948. Instituto de Estudios Hispánicos de Barcelona. Barcelona: Instituto de Estudios Hispánicos. 
Manjón, Dolores. 2007. «Poesía en castellano en Barcelona (1939-1950)». Tesi doctoral, UNED.

- 2008. «Poesía de Posguerra en Barcelona». Revista de Literatura 139: 141-163.

Marzo, José Luis. 2007. Art modern i franquisme. Els orígens conservadors de l'avantguarda i de la política artística a l'Estat espanyol. Girona: Fundació Espais d'Art Contemporani.

Masoliver, Juan Ramón. 1987. «Enraizado en su tierra, influido por Mallarmé». La Vanguardia, 19 ag., 22.

_ . 1994. «Sobre la literatura catalana en castellano», 428-442. Dins Juan Ramón Masoliver, Perfil de sombras. Barcelona: Destino.

Mendonça, Renato de. 1952. Antología de la poesía brasileña. Madrid: Ediciones Cultura Hispánica.

Miranda, António. s/d. Sobre Manuel Segalà, http://www.antoniomiranda.com.br/ editoras_e_editores_de_poesia/philobiblion.html.

Munné, Antoni. 1976. «Entrevista con Pere Gimferrer. Función de la poesía, función de la crítica». El Viejo Topo 26: 40-43.

Muñoz, Teresa. 2006. Josep M. Castellet. Retrat de personatge en grup. Barcelona: Edicions 62.

Neto, João Cabral de Melo. 1949. «Quinze poetas catalães». Revista Brasileira de Poesia 4: 29-43 i $65-66$.

- 2003a. Obra Completa. Rio de Janeiro: Nova Aguilar.

— 2003 b. Poesia e composição. A inspiração e o trabalho de arte. Coïmbra: Angelus Novus.

- 2008. Joan Miró. Barcelona: Casa Amèrica Catalunya.

- 2010. Revista Literária em Tradução 1. http://en.calameo.com/ read/ooo26o24543d2fgc28bo1.

Omer, Mordechai. 1972. Universo y magia de Joan Ponç. Barcelona: Ediciones Polígrafa.

Orico, Osvaldo. 1948. Poetas del Brasil. Madrid: Ediciones de Cuaderno de Literatura / Instituto Miguel de Cervantes / CSIC.

Peixoto, Fernanda Arêas. 2010. «Letras y diplomacia en el Brasil: una aproximación en tres tiempos», 98-118. Dins Carlos Altamirano, ed., Historia de los intelectuales en América Latina II. Buenos Aires: Katz.

Plata Parga, Gabriel. 2018. La frontera entre franquismo y antifranquismo. Colaboración cultural y ambigüedades ideológicas. Gijón: Ediciones Trea.

Pont, Jaume. 2007. «Una revista poètica de la immediata postguerra: Entregas de Poesía (Barcelona, 1944-1947). Trajectòria, programa i funció», 49-63. Dins Miquel M. Gibert, Amparo Hurtado i José Francisco Ruiz Casanova, ed., Literatura comparada catalana i espanyola al segle Xx: gèneres, lectures i traduccions (1898-1951). Lleida: Punctum / Trilcat.

Provencio, Pedro. 2003. «La Poesía en Cultura Hispánica», 57-71. Dins AA.DD., La huella editorial del Instituto de Cultura Hispánica. Ediciones Cultura Hispánica y otras publicaciones: estudios y catálogo (1944-1980). Madrid: Ministerio de Asuntos Exteriores / Fundación Mapfre Tavera. 
Puig, Arnau. 1980. «El poeta brasiler Jôao Cabral de Melo a Barcelona (1948-52)». L’Avenç 33: $772-775$.

ـ 2004. «Garcia Vilella. Les arrels d'un artista de la modernitat», 9-31. Dins Garcia Vilella. Barcelona: Àmbit.

Roh, Franz. 1927. Realismo mágico. Post expresionismo. Problemas de la pintura europea más reciente. Madrid: Revista de Occidente.

Santos, Margareth dos. 2012. «Un poema tirado al mar: contactos poéticos entre Carlos Drummond de Andrade y José Agustín Goytisolo». Filología y Lingüística 38: 63-74.

Santos, Rafael. 1951. «Introducción». Dins Carlos Drummond de Andrade, Poemas. Madrid: Rialp.

Segalá, Manuel. 1940. «Prólogo», 7-19. Antonio Ferreira. Selecció, traducció i pròleg de Manuel Segalá Brosa. Barcelona: Editorial Yunque.

Seguel, Gerardo. 1930. «Estructura de la actual poesía brasileña». La Gaceta Literaria 74: 5-6.

Serpa, Alberto de. 1943. As melhores poesias brasileiras. Lisboa: Portugália.

—. 1952. Poetas... Poetas... Diário do I Congresso de Poesia em Segóvia. Porto: Edições Saber.

Sousa, Carlos Mendes de. 200o. «Cartas de João Cabral de Melo para Clarice Lispector». Colóquio / Letras 157-158: 282-300.

Tàpies, Antoni. 1974. L'art contra l'estètica. Barcelona: Ariel.

- 2003. Memoria personal. Barcelona: Seix Barral.

- 2010. Memòria personal. Fragment per a una autobiografia. Obra escrita completa, I. Barcelona: Fundació Antoni Tàpies.

Torre, Alfonso de la. 2007. «Bienal de São Paulo (IV), 1957. La contradictoria presencia del arte Español». https://www.delatorrealfonso.com/2007/10/23/ bienal-de-sao-paulo-iv-1957-la-contradictoria-presencia-del-arte-espanol/.

Triadú, Joan, 1948. «Brasil i Catalunya». Ariel 16: 40.

Ungaretti, Giuseppe. 1977. Vida de un hombre. Caracas: Monte Ávila Editores.

Valbuena, Ángel. 1968. Historia de la literatura española, tom IV. Barcelona: Gustavo Gili. Vallès, Joan. 200o. Ramon Rogent i el seu entorn. Barcelona: Publicacions de l’Abadia de Montserrat.

Vázquez, Pilar. 1950. Bandeira-Drummond-Schmidt. Tres poetas del Brasil. Madrid: Artes Gráficas Evaristo San Miguel.

Vicens, Jaume. 1940. España. Geopolítica del Estado y del Imperio. Barcelona: Editorial Yunque.

Vidal, Jaume. 1997. «Cobalto, història d'una iniciativa editorial (1947-1953). Locvs Amonuvs 3: 215-240.

Villa-Lobos, Heitor. 1929. «O meu maior desejo é ver a música hespanhola livre de influências». Helix 7: 2-3. 